\title{
Requirement for Slit-1 and Robo-2 in Zonal Segregation of Olfactory Sensory Neuron Axons in the Main Olfactory Bulb
}

\author{
Jin Hyung Cho, ${ }^{1,2}$ Manon Lépine, ${ }^{1,2}$ William Andrews, ${ }^{3}$ John Parnavelas, ${ }^{3}$ and Jean-François Cloutier ${ }^{1,2}$ \\ ${ }^{1}$ Montreal Neurological Institute, Centre for Neuronal Survival, Montréal, Québec, Canada H3A 2B4, ${ }^{2}$ Department of Neurology and Neurosurgery, McGill \\ University, Montréal, Québec, Canada H3A 2B4, and ${ }^{3}$ Medical Research Council Centre for Developmental Neurobiology, King's College London, London \\ SE1 1UL, United Kingdom
}

The formation of precise stereotypic connections in sensory systems is critical for the ability to detect and process signals from the environment. In the olfactory system, olfactory sensory neurons (OSNs) project axons to spatially defined glomeruli within the olfactory bulb (OB). A spatial relationship exists between the location of OSNs within the olfactory epithelium (OE) and their glomerular targets along the dorsoventral axis in the $\mathrm{OB}$. The molecular mechanisms underlying the zonal segregation of OSN axons along the dorsoventral axis of the $\mathrm{OB}$ are poorly understood. Using robo- $2^{-/-}$(roundabout) and slit-1 ${ }^{-/-}$mice, we examined the role of the Slit family of axon guidance cues in the targeting of OSN axons during development. We show that a subset of OSN axons that normally project to the dorsal region of the $\mathrm{OB}$ mistarget and form glomeruli in the ventral region in robo- $2^{-/-}$and slit- $1^{-/-}$mice. In addition, we show that the Slit receptor, Robo-2, is expressed in OSNs in a high dorsomedial to low ventrolateral gradient across the OE and that Slit-1 and Slit-3 are expressed in the ventral region of the $\mathrm{OB}$. These results indicate that the dorsal-to-ventral segregation of OSN axons are not solely defined by the location of OSNs within the OE but also relies on axon guidance cues.

Key words: Slit; Robo; axon guidance; olfactory epithelium; olfactory bulb; glomerular targeting

\section{Introduction}

The accurate representation of stimuli from the environment relies on the formation of precise connections between sensory neurons in the periphery and second-order neurons in the CNS. Such stereotyped connections are crucial for the specific detection and perception of odorant molecules by the olfactory system. Olfactory sensory neurons (OSNs) that are located in the olfactory epithelium (OE) form highly stereotyped connections with second-order neurons within the olfactory bulb (OB). OSNs distributed within four spatially distinct zones of the OE project axons to four specific regions of the olfactory bulb (Strotmann et al., 1992, 1994; Ressler et al., 1993, 1994; Vassar et al., 1993, 1994; Mombaerts et al., 1996; Sullivan et al., 1996; Tsuboi et al., 1999). Although these zones are defined based on the segregated patterns of expression of odorant receptors in OSNs, there exists a certain degree of overlap in the expression patterns of olfactory receptors (ORs) within some of these zones (Norlin and

Received Dec. 16, 2006; revised July 6, 2007; accepted July 9, 2007.

This work was supported by the Canadian Institutes for Health Research, the Fonds Québécois pour la Recherche sur la Nature et les Technologies, and the Canada Foundation for Innovation. J.-F.C. holds a Canada Research Chair in developmental neurobiology. We thank Alyson Fournier, David Ginty, and Timothy Kennedy for comments on this manuscript and members of the Cloutier laboratory for helpful discussions. We are thankful to David Ornitz for Slit CDNA clones, Alain Chédotal for Robo cDNA clones, Tyler Cutforth for the OMP CDNA clone, and Zhiua Zhou and Linda Buck for the M50 and M5 CDNA clones. We also thank Marc Tessier-Lavigne for his generous gift of Slit-1 and Robo-2 mutant mice, Jeffrey Esko for providing us with the Slit-3 mutant mice with permission from David Ornitz, and David Ginty for synapsin-1 Cre mice.

Correspondence should be addressed to Jean-François Cloutier, Montreal Neurological Institute, Centre for Neuronal Survival, 3801 University, Montréal, Québec, Canada H3A 2B4. E-mail: jf.cloutier@mcgill.ca.

DOI:10.1523/JNEUROSCI.2217-07.2007

Copyright @ 2007 Society for Neuroscience $\quad$ 0270-6474/07/279094-11\$15.00/0
Berghard, 2001; Iwema et al., 2004; Miyamichi et al., 2005). Nonetheless, there is a strong correlation between the location of the OSN cell bodies within the OE and the targeting of their axons along the dorsoventral axis of the OB (Astic and Saucier, 1986; Saucier and Astic, 1986; Miyamichi et al., 2005). OSNs positioned in the dorsomedial aspect of the OE project to the dorsal region of the $\mathrm{OB}$, whereas neurons located in the ventrolateral region of the OE innervate the most ventral region of the OB (see Fig. $1 N$ ). The molecular mechanisms that orchestrate the segregation of OSN axons within distinct zones of the $\mathrm{OB}$ remain to be defined.

Within spatially defined zones of the OB, axons of OSNs expressing the same odorant receptor converge into two bilateral and stereotypically conserved glomeruli (Ressler et al., 1994; Vassar et al., 1994; Mombaerts et al., 1996). OR expression is required for convergence of OSN axons onto specific glomeruli within the OB (Mombaerts et al., 1996). Although the exact mechanism by which ORs regulate this convergence has not been fully defined, they may promote sorting of axons by favoring coalescence of axons expressing the same OR (Feinstein and Mombaerts, 2004; Feinstein et al., 2004). Alternatively, ORderived cAMP signals can regulate glomerular targeting of OSN axons (Imai et al., 2006; Chesler et al., 2007; Dal Col et al., 2007; Zou et al., 2007).

Because the OB is a three-dimensional structure, OSN axons must target to specific glomeruli by responding to signals that direct their growth along the mediolateral, anteroposterior, and dorsoventral axes of the OB. In addition to ORs, several families of axon guidance cues have emerged as important regulators of axonal targeting during formation of stereotyped connections in the olfactory system. Members of the secreted semaphorin 
(Sema) family and their receptors, the neuropilins, have been implicated in the development of OSN projections. (de Castro et al., 1999; Pasterkamp et al., 1999; Renzi et al., 2000; Schwarting et al., 2000; Walz et al., 2002; Cloutier et al., 2004; Schwarting et al., 2004). Indeed, Sema3A is required for appropriate medial to lateral targeting of OSN axons (Schwarting et al., 2000). Furthermore, differential expression of Ephrin A family members on OSN axons are required for their accurate anterior-to-posterior targeting in the OB (Cutforth et al., 2003). However, the molecules involved in the control of dorsal-to-ventral targeting of OSN axons within the OB have yet to be identified.

Members of the Robo (roundabout) family of axon guidance cue receptors have been implicated in the targeting of OSN axons in Drosophila and zebrafish (Jhaveri et al., 2004; Miyasaka et al., 2005). Moreover, we demonstrated previously that the Slit and Robo families of axon guidance cues can promote zonal segregation of vomeronasal axons in the accessory olfactory system in mice (Cloutier et al., 2004). We therefore evaluated whether SlitRobo signaling controls zonal segregation of OSNs in the main olfactory bulb. To evaluate the roles of Slits and Robos in the development of the olfactory system, we defined their patterns of expression in the olfactory system and analyzed OSN projections in mice lacking Slit ligands and the Slit receptor Robo-2. Our results show that Slit-1 and Robo-2 are essential for dorsoventral segregation of OSN axons within the OB.

\section{Materials and Methods}

Animals. Embryonic day 16 (E16) and E18 mouse embryos were obtained from timed-pregnant females purchased from Charles River (Saint-Constant, Quebec, Canada). Date of vaginal plug was considered as E0. Robo-2, slit-1, and slit-3 mutant mice have been described previously (Plump et al., 2002; Yuan et al., 2003; Grieshammer et al., 2004) and were generously provided by Dr. Marc Tessier-Lavigne (Genentech, San Francisco, CA) (robo-2 and slit-1) and Dr. Jeff Esko (University of California, San Diego, San Diego, CA) (slit-3). The floxed robo-2 mutant mouse has been described previously (Lu et al., 2007)

Generation of Robo-2 antibody. Anti-Robo-2 antibodies were produced by immunizing rabbits with a synthetic peptide from the C-terminal region of Robo-2 (CLRGSHQRNANDLLDI) coupled to keyhole limpet hemocyanin. Rabbits were immunized with $250 \mu \mathrm{g}$ of coupled peptide in complete Freund's adjuvant and boosted every $2-3$ weeks with $100 \mu \mathrm{g}$ of coupled peptide. Serum was collected, and antibodies were purified with an affinity column prepared using the SulfoLink kit from Pierce (Rockford, IL). The specificity of the purified antibodies for Robo-2 was determined by immunoblot analysis using extracts of Robo-1- or Robo-2-transfected human embryonic kidney HEK293T cells (data not shown) and by immunostaining on sections of olfactory bulbs from E18 wild-type and robo- $2^{-/-}$mice (supplemental Fig. 1, available at www.jneurosci.org as supplemental material).

In situ hybridization. Nonradioactive, digoxigenin (DIG)-labeled cRNA probes with either sense or antisense orientation were synthesized by in vitro transcription using DIG labeling mix (Roche, Mannheim, Germany) according to the recommendations of the manufacturer. Probes were synthesized from cDNA clones encoding robo-1 and robo-2 (Brose et al., 1999), slit-1, slit-2, and slit-3 (Yuan et al., 1999), OMP (olfactory marker protein) (Cutforth et al., 2003), NQO-1 (NADPH: quinone oxidoreductase) [Expressed Sequence Tag (EST) IMAGE number 3586888], rig-1 (retinoblastoma-inhibiting gene) (EST IMAGE number 6834877), OCAM (olfactory cell adhesion molecule) (PCRamplified coding region), and M50 (Zou et al., 2001). To prepare M49, L45, K21, and M72-specific cRNA probes, DNA fragments of the coding sequences were PCR amplified from C57BL/6 genomic DNA and subcloned into the pBluescript vector. The primer sets used were as follows: M49, 5' -CCGAATCGTTTGGGAGGAGGCTT-3' and 5'-CACTCGAGAGCTCTTCCTAGTACC-3'; L45, 5'-CCGAATTCACGAGAGCATCACAGG-3' and 5'-CACTCGAGGCAATAATTCCATAGA- $3^{\prime} ; \mathrm{K} 21,5^{\prime}$ -
CCGAATCATGCCCCTCTTCTTC-3' and $5^{\prime}$-CACTCGAGGCTCAATGTTTTTCTC-3'; and M72, 5'-CCGAATCGAGGGCTAACTAACAG-3' and 5'-CACTCGAGCAGTGCGGTCTTCACC-3'. For in situ hybridization on E16 and E18 embryos, as well as postnatal day 0 (P0) mice, fresh frozen brains were cryosectioned at $20 \mu \mathrm{m}$ and sections were allowed to dry for $2 \mathrm{~h}$. After fixation, sections were processed as described previously (Cloutier et al., 2002). For in situ hybridization on adult (3-4 months old) olfactory epithelium, mice were transcardially perfused with PBS containing $4 \%$ paraformaldehyde. The nasal cavity was dissected, postfixed in paraformaldehyde containing $0.5 \mathrm{M}$ EDTA in PBS for 3-5 d for decalcification, and cryoprotected in PBS containing 30\% sucrose before freezing. The olfactory epithelium was cryosectioned at $20 \mu \mathrm{m}$, and sections were processed as described previously (Cloutier et al., 2002).

Immunohistochemical procedures. Adult mice were anesthetized and perfused transcardially with ice-cold PBS containing 4\% paraformaldehyde. Brains were dissected, postfixed for 3-5 h in perfusion solution, and cryoprotected in PBS containing 30\% sucrose. Alternatively, E16 and E18 embryos and P0 mouse heads were immersion fixed overnight in PBS containing $4 \%$ paraformaldehyde, followed by cryoprotection in PBS containing 30\% sucrose. The samples were cryosectioned $(20 \mu \mathrm{m})$, mounted on superfrost plus microscope slides, and allowed to dry for $1 \mathrm{~h}$. The sections were rinsed twice in TBS ( $50 \mathrm{~mm}$ Tris- $\mathrm{HCl}, \mathrm{pH}$ 7.6, and 150 $\mathrm{mm} \mathrm{NaCl}$ ), microwaved 10 times for $30 \mathrm{~s}$ in $100 \mathrm{~mm}$ Tris- $\mathrm{HCl}, \mathrm{pH}$ 10, for antigen retrieval, and allowed to cool down for $20 \mathrm{~min}$ at room temperature. The sections were then blocked for $2 \mathrm{~h}$ in TNT ( $50 \mathrm{~mm}$ Tris- $\mathrm{HCl}$, $\mathrm{pH} 7.6,500 \mathrm{~mm} \mathrm{NaCl}$, and $0.5 \%$ Triton X-100) containing $10 \%$ fetal bovine serum (FBS) and incubated overnight with primary antibody at $4^{\circ} \mathrm{C}$ in TNT $/ 10 \%$ FBS using the following dilutions: anti-OCAM at 1:100 (BD Biosciences, San Jose, CA), anti-NQO-1 at 1:100 (Abcam, Cambridge, MA), anti-SV2 (synaptic vesicle protein 2) at 1:1000 (Developmental Studies Hybridoma Bank, University of Iowa, Iowa City, IA), and anti-Robo-2 at 1:350. After rinsing in TBS, primary antibody was detected with the appropriate Alexa-488- or Alexa-546-conjugated secondary antibody (1:500; Invitrogen, Carlsbad, CA) in TNT/10\% FBS.

Analysis of the position of NQO-1-positive glomeruli in adult olfactory bulbs. Adult mice were anesthetized and perfused transcardially with ice-cold PBS containing 4\% paraformaldehyde. Brains were dissected, postfixed for $3-5 \mathrm{~h}$ in perfusion solution, and cryoprotected in PBS containing 30\% sucrose. Brains were then laid flat, ventral side down, in a rectangular chamber, and a cut was made perpendicular to the surface of the cortex at similar rostrocaudal levels. The olfactory bulbs and remaining forebrain were then mounted with the cut side of the forebrain lying flat on a chuck for cryosectioning. OBs from 3-month-old mice were cryosectioned $(20 \mu \mathrm{m})$ in the coronal plane, and sections were collected on microscope slides over a distance of $1000 \mu \mathrm{m}$ along the rostrocaudal axis starting $800 \mu \mathrm{m}$ from the tip of the OB. All sections were immunostained with NQO-1 and OCAM antibodies and counterstained with Hoechst as described above. The position of all NQO-1-positive glomeruli in the OB was determined using an NIH Image J plug-in as described previously (Schaefer et al., 2001). An NQO-1-positive glomerulus was defined as a region of the neuropil that contains NQO-1-positive immunoreactivity and that is surrounded by periglomerular cells. Briefly, images of every other sections were imported into Adobe Photoshop software (Adobe Systems, Mountain View, CA) for mapping of glomeruli. The radial angle of each NQO-1-positive glomeruli was measured after setting the origin for each section. The origin was set at one-third the distance between the mitral cell layer in the dorsal region of the $\mathrm{OB}$ and the mitral cell layer in the ventral region of the OB. A scatter plot was constructed that shows the location of each NQO-1-positive glomerulus with degrees (angle) on the $y$-axis and the rostrocaudal distance on the $y$-axis.

\section{Results}

\section{Robo-2 expression by olfactory sensory neurons}

The molecular cues that coordinate the zonal segregation of OSN axons in the $\mathrm{OB}$ are unknown. Previous studies showed that Robo-2 is expressed in the OE during early development (Marillat et al., 2002). To begin to assess the involvement of Slits and their receptors, the Robos, in guidance of OSN projections, we 


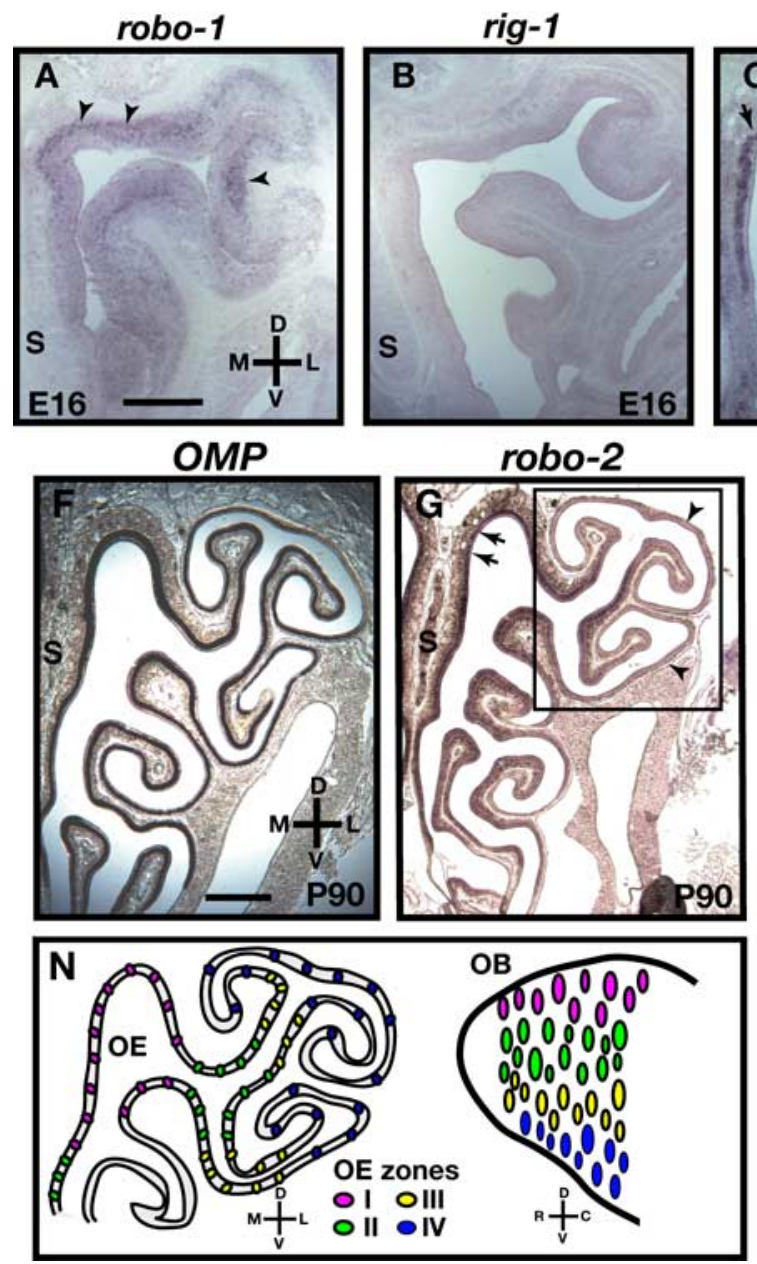

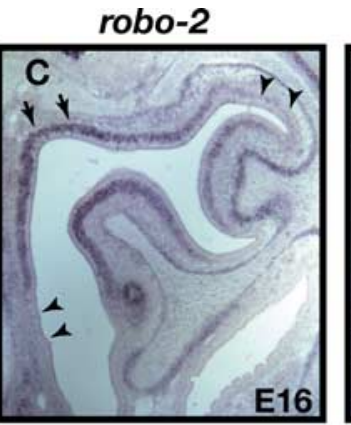
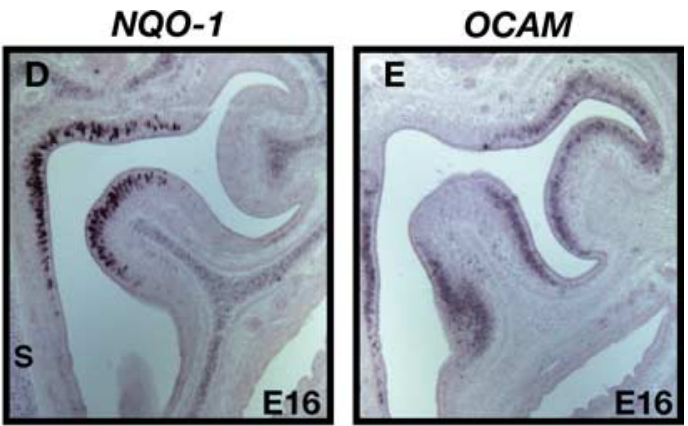

\section{robo-2}
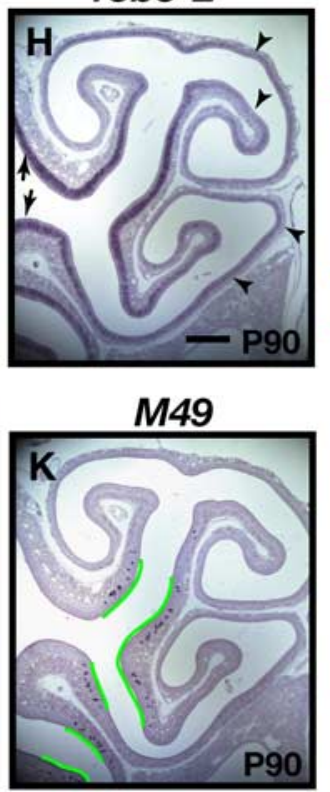

OCAM

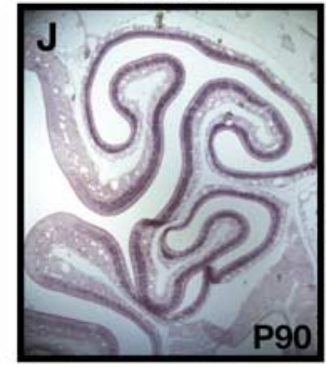

M50
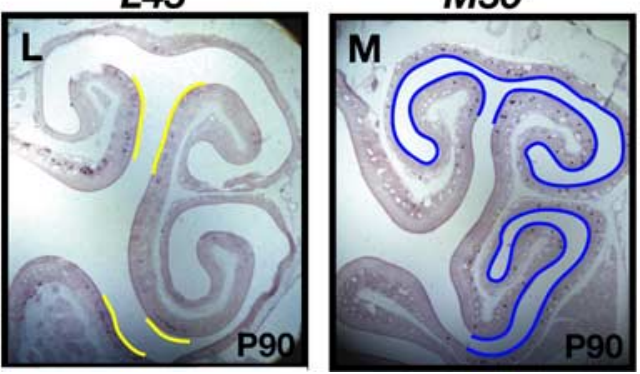

Figure 1. Expression of Robo family members in the olfactory epithelium. In situ hybridization of coronal sections of olfactory epithelium isolated from E16 embryos (A-E) and adult mice (P90)

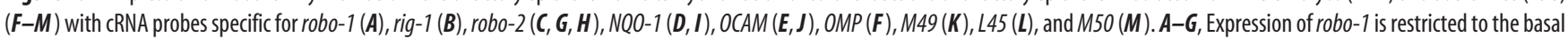
lamina of the olfactory epithelium (A, arrowheads), whereas rig- 1 is not expressed in the olfactory epithelium $(\boldsymbol{B})$. Interestingly, in contrast to $0 \mathrm{MP}$, which is equally expressed throughout the olfactory epithelium, robo- 2 is expressed in a gradient with high levels of expression in the dorsomedial regions of the olfactory epithelium (arrows) and low levels in the ventrolateral regions (arrowheads) of E16 $(\boldsymbol{C})$ and adult olfactory epithelium $(\boldsymbol{G}, \boldsymbol{H}) . \boldsymbol{H}-\mathbf{M}$, robo-2 expression is confined to zones I-III of the olfactory epithelium. A higher magnification of a region of the olfactory epithelium (boxed in $\boldsymbol{G}$ ) in which all four zones of the olfactory epithelium are represented is shown in $\boldsymbol{H}-\boldsymbol{M}$. The expression pattern of robo- 2 was compared with the expression pattern of specific olfactory epithelium zonal markers that include NQ0-1 (zone I) (I), OCAM (zones II-IV) (J), M49 (zone II) (K), L45 (zone III) (L), and M50 (zone IV) ( $\boldsymbol{M}$ ). robo-2 is expressed in a high-to-low gradient in olfactory sensory neurons located in zones I (arrows) to IV (arrowheads), respectively. Regions of the olfactory epithelium expressing the different zonal markers are traced with a colored line on the apical surface of the olfactory epithelium to represent the four zones (zone I, magenta; zone II, green; zone III, yellow; zone IV, blue). S, Septum. Scale bars: A-E, H-M, $250 \mu \mathrm{m} ; \boldsymbol{F}, \mathbf{G}, 500 \mu \mathrm{m}$. $N$, Diagram representing the spatial relationship between the location of olfactory sensory neurons within the $0 \mathrm{E}$ and their target glomeruli within the $0 B$. Olfactory sensory neurons located in the dorsomedial regions of the olfactory epithelium (magenta) project axons to glomeruli in the dorsal region of the olfactory bulb, whereas olfactory sensory neurons in the ventrolateral region of the olfactory epithelium (blue and not shown) project axons to the ventral aspect of the olfactory bulb. D, Dorsal; V, ventral; L, lateral; M, medial; R, rostral; C, caudal.

performed in situ hybridization analyses of the robo family members robo-1, robo-2, and rig-1 to determine their patterns of expression in the developing olfactory system.

Whereas rig- 1 is not expressed in the $\mathrm{OE}$, robo- 1 expression is restricted to the basal lamina surrounding the OE (Fig. 1A,B). rig- 1 expression was detected in other structures on these sections including the retina (data not shown). In contrast to rig-1 and robo-1, robo-2 is highly expressed in the OE at E16 (Fig. 1C) and E18 (data not shown), developmental ages when OSN axons have reached the $\mathrm{OB}$ and have begun to form protoglomeruli, respectively. Interestingly, robo-2 expression in the OE at E16 is graded with high levels detected in the dorsomedial region and low levels in the ventrolateral region (Fig. 1C). OE regions expressing high levels of robo-2 overlap with the region containing NQO-1expressing OSNs, which are located in zone I of the OE according to the nomenclature defined by Sullivan et al. (1996) (Fig. 1C,D) (Gussing and Bohm, 2004). Robo-2 expression also partially over- laps regions of the OE containing OCAM-expressing OSNs that define zones II-IV of the OE (Fig. 1C,E) (Alenius and Bohm, 1997; Yoshihara et al., 1997). To further ask whether OSNs located in specific zones of the OE express robo-2, we compared its pattern of expression with the expression of specific OR in the adult $\mathrm{OE}$. In contrast to $\mathrm{OMP}$, and as observed at E16, robo-2 expression is graded in the adult $\mathrm{OE}$ with the highest levels of expression observed in the dorsomedial region of the OE (Fig. $1 F, G)$. We compared robo-2 expression with the expression of molecules expressed in specific zones of the OE: NQO-1 (zone I), OCAM (zones II-IV), M49 (zone II), L45 (zone III), and M50 (zone IV) (Fig. 1I-M) (Sullivan et al., 1996). This comparison revealed that OSNs located in zones I and II of the OE express the highest levels of robo-2, whereas OSNs of zones III express lower levels, and OSNs in zone IV do not express detectable levels of robo- 2 .

To address whether the graded expression of robo-2 observed 

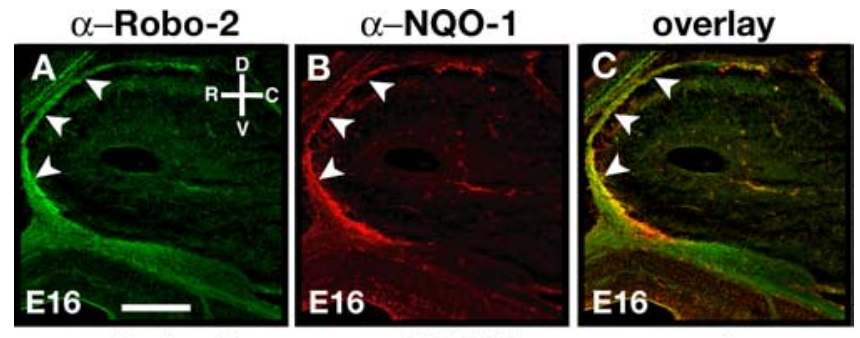

$\alpha-$ Robo-2

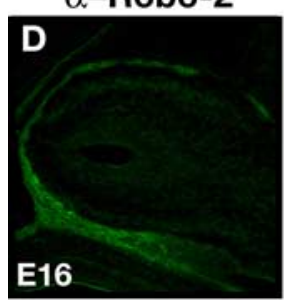

$\alpha-$ Robo-2

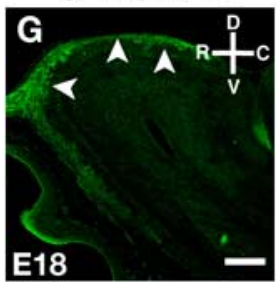

$\alpha-$ Robo-2

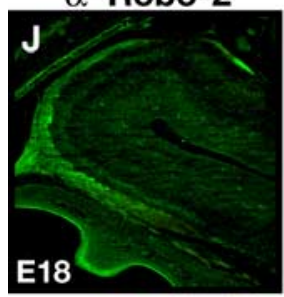

$\alpha-$ Robo-2

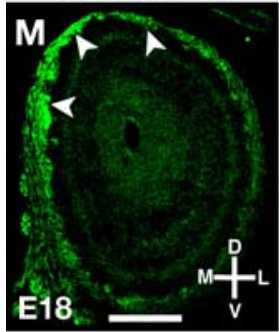

$\alpha-$ Robo-2

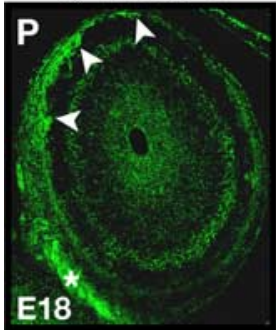

$\alpha-$ OCAM
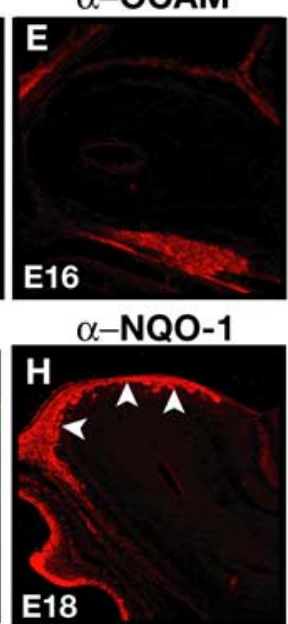

$\alpha-$ OCAM

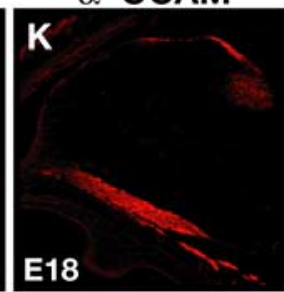

$\alpha-\mathbf{N Q O - 1}$

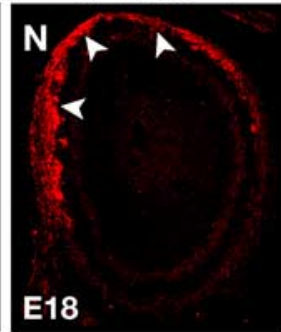

$\alpha-$ OCAM

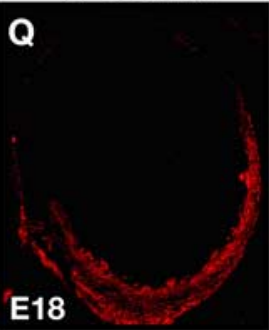

$\alpha-\mathbf{N Q O}-1$
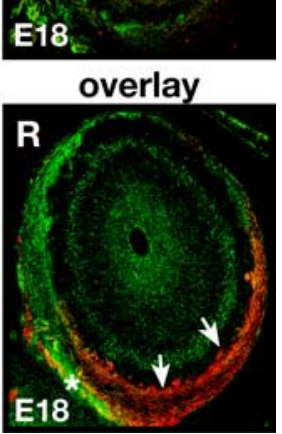

in OSNs of the OE is reflected by the distribution of Robo-2 protein on axons targeting to the $\mathrm{OB}$, we generated antibodies against a C-terminal peptide of Robo-2. Immunohistochemical analysis using these Robo-2-specific antibodies revealed that Robo-2 is highly expressed on OSN axons that project to the dorsal (Fig. 2A,D,G,J) and dorsomedial (Fig. 2M,P) aspects of the $\mathrm{OB}$ at E16 and E18. No immunoreactivity was detected in sections of $\mathrm{OB}$ from robo- $2^{-/-}$mice, demonstrating that our antibody specifically recognizes Robo-2 (supplemental Fig. $1 D, F$, available at www.jneurosci.org as supplemental material). A large proportion of OSN axons that express high levels of Robo-2 originate from OSNs located in zone I of the OE that express NQO-1 (Fig. $2 A-C, G-I, M-O)$. Robo-2 is also expressed, albeit at lower levels, on OSN axons that target more ventrally in the OB. Whereas some of the Robo-2-positive axons express OCAM, a subset of OCAM-positive axons that target to the most ventral aspect of the $\mathrm{OB}$ are devoid of Robo-2 expression (Fig. $2 D-F, J-L, P-R)$. This observation is consistent with the results obtained by in situ hybridization showing overlap of robo-2 and OCAM expression in zone II of the OE (Fig. $1 \mathrm{H}, J, K$ ). Together, these observations indicate that Robo- 2 is a candidate for imparting guidance information to OSN axons as they project to the OB.

Expression of slits in the ventral region of the olfactory bulb The graded expression of robo- 2 across the OE suggests that axons of OSNs located in specific regions of the OE may respond differently to Robo-2 ligands expressed in their target field. In situ hybridization experiments revealed that two members of the Slit family of proteins are expressed in the OB. slit-2 expression is not detected in sagittal sections of the OB at E16 and E18, whereas slit-1 and slit-3 are highly expressed in the ventral region of the OB (Fig. 3A-L). slit-2 expression was detected in other regions of the brain in the same sections, including the developing cortex (data not shown). Interestingly, whereas slit-1 expression is restricted to a small subset of cells located in the ventral most region of the $\mathrm{OB}$ at E18, the distribution of slit-3 expression remains unchanged at this later stage of development (Fig. $3 D, F$ ). Similar patterns of expression were observed in coronal sections of the OB in which slit-1 and slit-3 are highly expressed in the ventrolateral region and at lower levels in the ventromedial region of the OB (Fig. 3G, $I, J, L$ ). This pattern of expression of the Slit-1 and Slit-3 chemorepellents supports the possibility that axons of Robo-2-expressing OSNs are guided toward the dorsal region of the OB through Slit-Robo repulsion.

Figure 2. Targeting of Robo-2-expressing olfactory sensory neuron axons in the olfactory bulb. $\boldsymbol{A}-\boldsymbol{L}$, Parasagittal sections of olfactory bulbs from E16 $(\boldsymbol{A}-\boldsymbol{F})$ and E18 $(\boldsymbol{G}-\boldsymbol{L})$ embryos stained with anti-Robo-2 $(\boldsymbol{A}, \boldsymbol{C}, \boldsymbol{D}, \boldsymbol{F}, \boldsymbol{G}, \boldsymbol{I}, \boldsymbol{J}, \boldsymbol{L})$, anti-NQO-1 $(\boldsymbol{B}, \boldsymbol{C}, \boldsymbol{H}, \boldsymbol{I})$, and anti-OCAM $(\boldsymbol{E}, \boldsymbol{F}, \boldsymbol{K}$, L). At E16 and E18, olfactory sensory neuron axons expressing high levels of Robo-2 are observed in the dorsal and rostral regions of the $O B(A, D, G, J)$. Robo-2 is also expressed at lower levels on a subset of axons targeting the ventral region of the olfactory bulb. NQ0-1-expressing axons, originating from zone l of the olfactory epithelium, that target to the dorsal region of the OB express high levels of Robo-2 (B, $\boldsymbol{C}, \boldsymbol{H}, \boldsymbol{I})$ (arrowheads). A subset of OCAM-expressing axons that originate from zones II-IV of the olfactory epithelium and target to the ventral region of the

\section{OSN projections are disorganized in robo- $2^{-/-}$mice}

We next examined the integrity of olfactory projections in mice harboring a null mutation in robo-2. In light of the perinatal lethality of robo- $2^{-/-}$mice, we performed our analyses at $\mathrm{P} 0$ when OSN axons have begun to form glomeruli within the $\mathrm{OB}$ (Grieshammer et al., 2004). At this stage of development, the OB of robo- $2^{-/-}$mice is smaller and their accessory olfactory bulb is

olfactory bulb do not express Robo-2 (arrow) $(\boldsymbol{E}, \boldsymbol{F}, \boldsymbol{K}, \boldsymbol{L}) . \boldsymbol{M}-\boldsymbol{R}$, Coronal sections of olfactory bulbs from E18 embryos stained with anti-Robo-2 $(\boldsymbol{M}, \mathbf{O}, \boldsymbol{P}, \boldsymbol{R})$, anti-NQ0-1 $(\boldsymbol{N}, \mathbf{O})$, and antiOCAM $(\boldsymbol{Q}, \boldsymbol{R})$. At E18, olfactory sensory neuron axons expressing high levels of Robo-2 are observed in the dorsomedial regions of the $\mathrm{OB}$ (arrowheads), whereas lower levels of Robo-2 expression are observed on olfactory sensory neuron axons targeting to the ventrolateral region of the $\mathrm{OB}$. As observed in sagittal sections ( $\mathbf{G}-\boldsymbol{L})$, NQ0-1-positive axons express high levels of Robo-2 (arrowheads) $(\boldsymbol{M}-\mathbf{0})$, whereas a subset of OCAM-positive axons do not express Robo-2 (arrows) $(\boldsymbol{P}-\boldsymbol{R})$. Robo-2-positive axons restricted to the nerve layer are marked with asterisks in $\boldsymbol{P}$ and $\boldsymbol{R}$. D, Dorsal; V, ventral; R, rostral; C, caudal; M, medial; L, lateral. Scale bars, $250 \mu \mathrm{m}$. 
underdeveloped when compared with robo- $2^{+/+}$mice. Nonetheless, in most robo- $2^{-1-}$ mice analyzed, the majority of OSN axons have reached and innervated the OB. To evaluate the accuracy of OSN axon targeting, sagittal and coronal sections of OB from $\mathrm{P} 0$ robo- $2^{+/+}$, robo- $2^{+/-}$ (data not shown), and robo- $2^{-1-}$ mice were stained with NQO-1 and OCAM antibodies to visualize axons originating from OSNs located in zone I and zones II-IV of the OE, respectively. In wild-type mice, NQO-1- and OCAM-expressing OSN axons are segregated to the rostrodorsal and ventral regions of the $\mathrm{OB}$, respectively (Fig. 4A-C). A similar segregation of NQO-1- and OCAM-expressing axons is observed in coronal sections in which these axons target to the dorsomedial and ventrolateral aspects of the $\mathrm{OB}$, respectively (Fig. 4G,I). In contrast, a subset of NQO-1-expressing OSN axons project inappropriately to the ventral region of the $\mathrm{OB}$ in robo- $2^{-1-}$ mice (Fig. $4 D, F, J, L, M, O$ ). Ectopic NQO-1-positive axons are detected at several levels along the rostrocaudal axis of the $\mathrm{OB}$ in all mice analyzed (Fig. 4) (supplemental Fig. 3, available at www.jneurosci.org as supplemental material). However, we did not observe any mistargeted OCAMexpressing OSN axons in the most dorsal region of the $\mathrm{OB}$ in robo- $2^{-/-}$mice (Fig. $4 E, F, K, L, N, O)$. Nonetheless, we observed that some regions of the ventral $\mathrm{OB}$ that are normally innervated by OCAM-expressing axons lack innervation in these mice (Fig. $4 K, L, N, O)$. The severity of this defect varies from animal to animal, with some mice having small regions that lack innervation (6 of 11 mice) (Fig. $4 K, L)$ and others lacking innervation in a large part of the ventral region of the $\mathrm{OB}$ (Fig. $4 \mathrm{~N}, \mathrm{O}$ ). In mice lacking innervation in the ventral region of the $\mathrm{OB}$, OCAM-expressing axons appear to remain trapped in the olfactory nerve layer and do not enter the glomerular layer of the $\mathrm{OB}$ (data not shown).

To determine whether mistargeted NQO-1-positive axons observed in the ventral region of the $\mathrm{OB}$ in robo- $2^{-/-}$mice result from deregulated expression of

NQO-1 or of other robo family members in OSNs, we assessed the patterns of expression of NQO-1, OCAM, robo-1, and rig- 1 in the $\mathrm{OE}$ of these mice. As observed in wild-type mice, NQO-1 expression is restricted to the dorsomedial region of the $\mathrm{OE}$, whereas OCAM expression is restricted to more ventrolateral regions of the $\mathrm{OE}$ in robo- $2^{-/-}$mice (Fig. $5 A, C, D, F$ ). Furthermore, as observed in wild-type mice, robo-1 and rig-1 are not expressed in the OE of robo- $2^{-/-}$mice (Fig. $5 K, N$ ). Hence, ablation of Robo-2 expression does not affect the expression patterns of NQO-1, OCAM, robo-1, and rig-1 in OSNs. In addition, the zonal segregation of zone I OR expression was unaltered in robo- $2^{-/-}$mice (supplemental Fig. 2, available at www.jneuro- slit-2
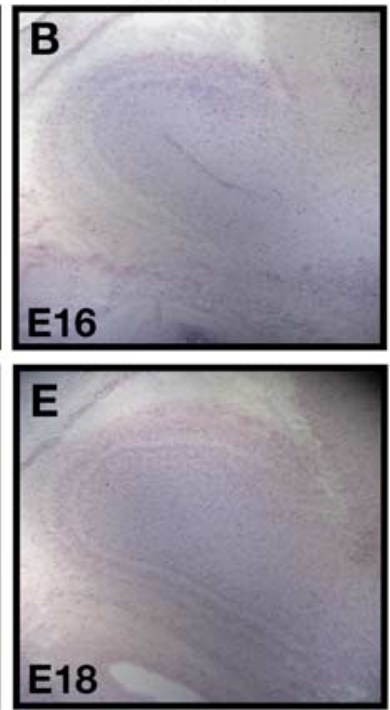

slit-2
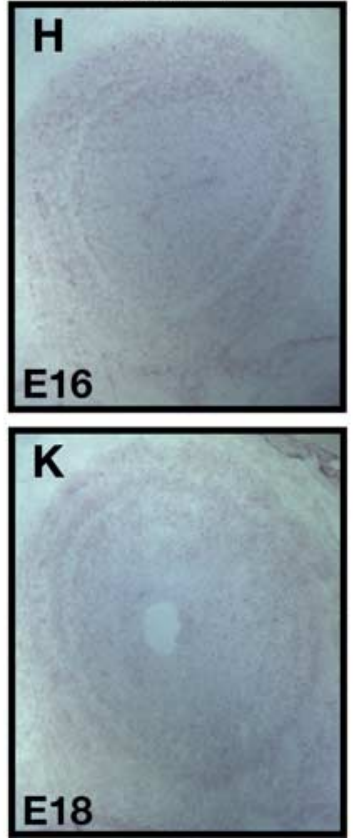

E16

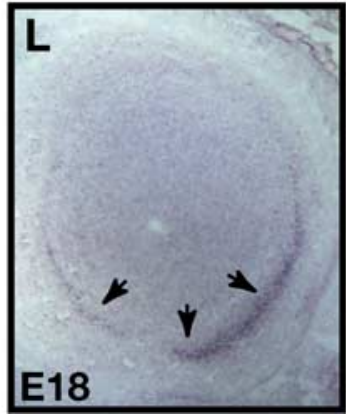

Figure 3. Expression of slits in the olfactory bulb. $\boldsymbol{A}-\boldsymbol{L}$, In situ hybridization of parasagittal $(\boldsymbol{A}-\boldsymbol{F})$ and coronal $(\boldsymbol{G}-\boldsymbol{L})$ sections of olfactory bulb at E16 ( $\boldsymbol{A}-\boldsymbol{C}, \boldsymbol{G}-\boldsymbol{I})$ and E18 (D-F, J-L) with cRNA probes specific for slit-1 $(\boldsymbol{A}, \boldsymbol{D}, \boldsymbol{G}, \boldsymbol{J})$, slit-2 $(\boldsymbol{B}, \boldsymbol{E}, \boldsymbol{H}, \boldsymbol{K})$, and slit-3 $(\boldsymbol{C}, \boldsymbol{F}, \boldsymbol{I}, \boldsymbol{L})$. At E16, whereas slit-2 is not expressed in the olfactory bulb $(\boldsymbol{B}, \boldsymbol{H})$, slit- $\boldsymbol{(}(\boldsymbol{A}, \boldsymbol{G})$ and slit-3 $(\boldsymbol{C}, \boldsymbol{I})$ are expressed in the ventral region of the olfactory bulb (arrows). These patterns of expression are maintained at E18 for slit-2 $(\boldsymbol{E}, \boldsymbol{K})$ and slit-3 $(\boldsymbol{F}, \boldsymbol{L})$ whereas slit- 1 expression is restricted to the most ventral region of the $0 B$ at $E 18(\boldsymbol{D}, J)$ (arrows). D, Dorsal; V, ventral; L, lateral; $M$, medial; $R$, rostral; $C$, caudal. Scale bars, $250 \mu \mathrm{m}$.

sci.org as supplemental material). These results indicate that Robo-2 is required for the accurate targeting of NQO-1expressing OSN axons to the dorsal region of the OB.

\section{Mistargeting of NQO-1-expressing OSN axons in Slit-1} mutant mice

The distribution of Slits in the OB, combined with the defects observed in the projections of OSN axons in robo- $2^{-/-}$mice suggests that Slits provide guidance information to OSN axons. To determine whether Slits are required for the segregation of NQO-1-expressing axons to the dorsal region of the OB, we analyzed these projections in slit-1 or slit-3 mutant mice, as well as 


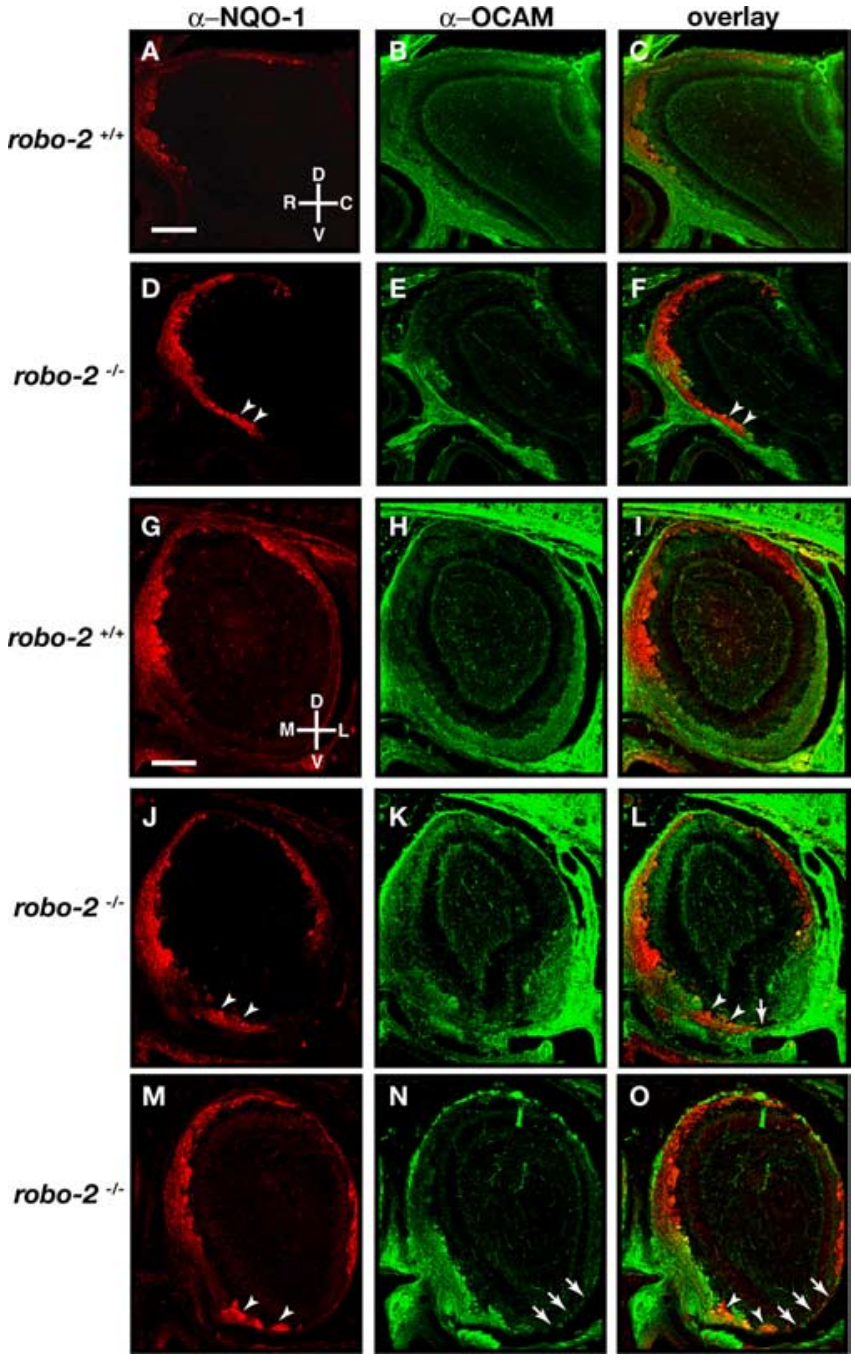

Figure 4. Olfactory sensory neuron projections are disorganized in robo- $2^{-/-}$mice. Parasagittal $(\boldsymbol{A}-\boldsymbol{F})$ and coronal $(\mathbf{G}-\mathbf{0})$ sections of olfactory bulbs from P0 robo-2 $2^{+/+}(\boldsymbol{A}-\boldsymbol{C}, \mathbf{G}-\boldsymbol{I})$

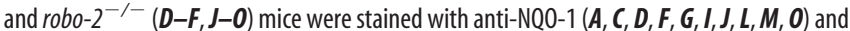
anti-OCAM ( $\boldsymbol{B}, \boldsymbol{C}, \boldsymbol{E}, \boldsymbol{F}, \boldsymbol{H}, \boldsymbol{I}, \boldsymbol{K}, \boldsymbol{L}, \boldsymbol{N}, \mathbf{O})$. In robo-2 ${ }^{-/-}$mice, NQ0-1-expressing axons are restricted to the rostral and dorsal region of the olfactory bulbs $(A, G)$, whereas 0 CAM-expressing axons target the ventral region of the olfactory bulbs $(\boldsymbol{B}, \boldsymbol{H})$. A subset of NQ0-1-expressing axons is mistargeted to the ventral region of the olfactory bulbs in robo-2 $2^{-1-}$ mice (arrowheads) $(\boldsymbol{D}, \boldsymbol{F}, \boldsymbol{J}, \boldsymbol{L}, \boldsymbol{M}, \mathbf{0})$. In addition, some regions of the ventral olfactory bulb that are innervated by OCAM-expressing axons in robo- $2^{+/+}$mice lack innervation in robo- $2^{-/-}$mice (arrows). $n=9$ robo- $2^{+/+}, 3$ robo- $2^{+/-}$, and 11 robo- $2^{-/-}$. D, Dorsal; V, ventral; L, lateral; $M$, medial; R, rostral; C, caudal. Scale bars, $250 \mu \mathrm{m}$.

in slit-1; slit-3 double-mutant mice. In contrast to what we observed in robo- $2^{-/-}$mice, the size of the $\mathrm{OB}$ is unaffected in slit $-1^{-/-}$mice at P0. However, a subset of slit- $3^{-/-}$and slit- $1^{-/-}$; slit- $3^{-/-}$mice analyzed showed a slight reduction in the size of their OBs. For axon targeting analysis, sagittal sections of $\mathrm{P} 0 \mathrm{OB}$ from wild-type, slit- $1^{-/-}$, slit- $3^{-/-}$, and slit- $1^{-/-} ;$slit- $3^{-/-}$mice were immunostained with NQO-1 and OCAM antibodies to visualize the two populations of OSN axons. Although NQO-1expressing axons are accurately segregated to the rostrodorsal regions in sagittal sections of the $\mathrm{OB}$ in wild-type and slit-3 $3^{-1-}$ mice (Fig. $6 A, C, H, J$ ), a subset of NQO-1-expressing axons mistarget to the most caudoventral region of the $\mathrm{OB}$ in slit- $1^{-/-}$ and slit- $1^{-/-}$; slit- $3^{-/-}$mice (Fig. $6 D, F, K, M$ ). Similar results were observed in coronal sections of the OB. Whereas NQO-1expressing axons are restricted to the dorsomedial region of the

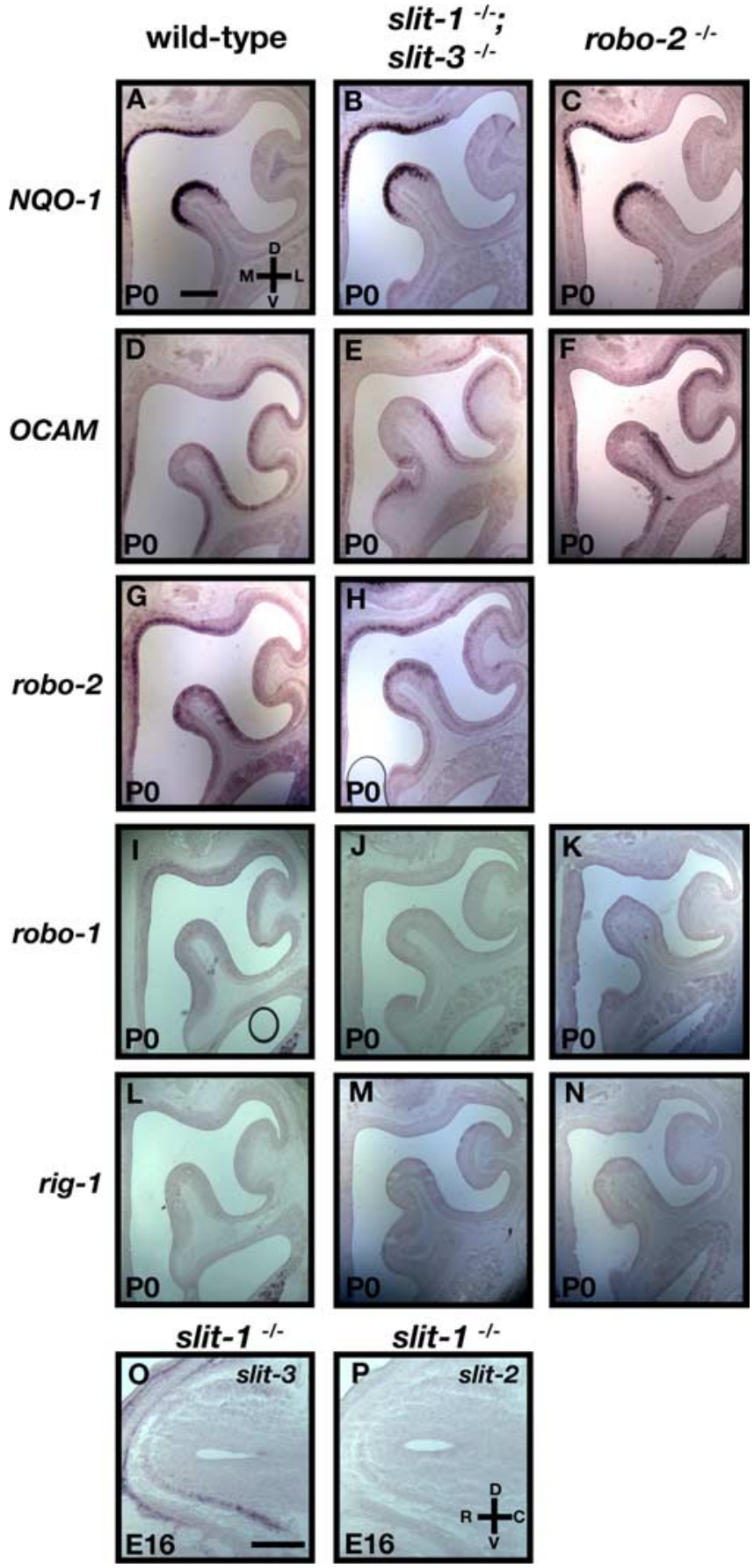

Figure 5. Expression of NQO-1 and OCAM are unaltered in robo-2-/- and slit- $1^{-/-}$; slit$3^{-1-}$ mice. $A-N$, In situ hybridization of coronal sections of olfactory epithelia from PO wild-

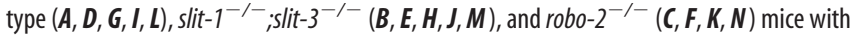
CRNA probes specific for NQO-1 (A-C), OCAM $(\boldsymbol{D}-\boldsymbol{F})$, robo-2 $(\mathbf{G}, \boldsymbol{H})$, robo-1 (I-K), and rig-1 $(\boldsymbol{L}-\boldsymbol{N})$. robo-2 is expressed in a gradient in the $0 \mathrm{E}$ with high levels of expression in the dorsomedial region of the $\mathrm{OE}$ and low levels in the ventrolateral region in wild-type $(G)$ and slit- $1^{-1}$ slit- $3^{-1-}(\boldsymbol{H})$ mice. NQO-1 is expressed in the dorsomedial region, whereas OCAM is expressed in the ventrolateral region of the olfactory epithelium in wild-type $(A, D)$, slit- $1^{-/} ;$; slit- $3^{-/-}$ $(\boldsymbol{B}, \boldsymbol{E})$, and robo-2 $2^{-1-}(\boldsymbol{C}, \boldsymbol{F})$ mice. Both robo- 1 and rig-1 are not expressed in the olfactory epithelium in wild-type $(\boldsymbol{I}, \boldsymbol{L})$, slit- $-^{-/-} ;$slit- $3^{-/-}(\boldsymbol{J}, \boldsymbol{M})$, and robo- $2^{-/-}(\boldsymbol{K}, \boldsymbol{N})$ mice. $n=5$ robo- $2^{-1-}$ and $n=5$ slit $-1^{-1-} ;$ slit- $3^{-1-} . \mathbf{O}, P$, In situ hybridization of parasagittal sections of olfactory bulbs from E16 slit- $1^{-1-}$ embryos with cRNA probes specific for slit-3 $(\mathbf{0})$ and slit-2 (P). Whereas slit-3 is expressed in the ventral region of the olfactory bulb, slit-2 is not expressed in the olfactory bulb of slit- ${ }^{-/-}$embryos. $n=3$ slit- ${ }^{-/-}$. D, Dorsal; V, ventral; L, lateral; $M$, medial; R, rostral; C, caudal. Scale bars, $250 \mu \mathrm{m}$. 

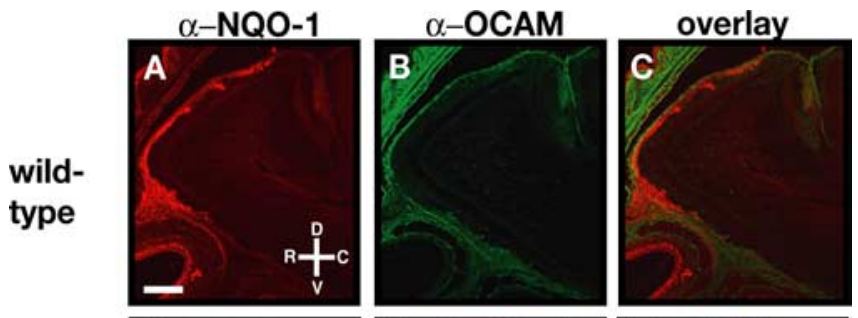

slit-1
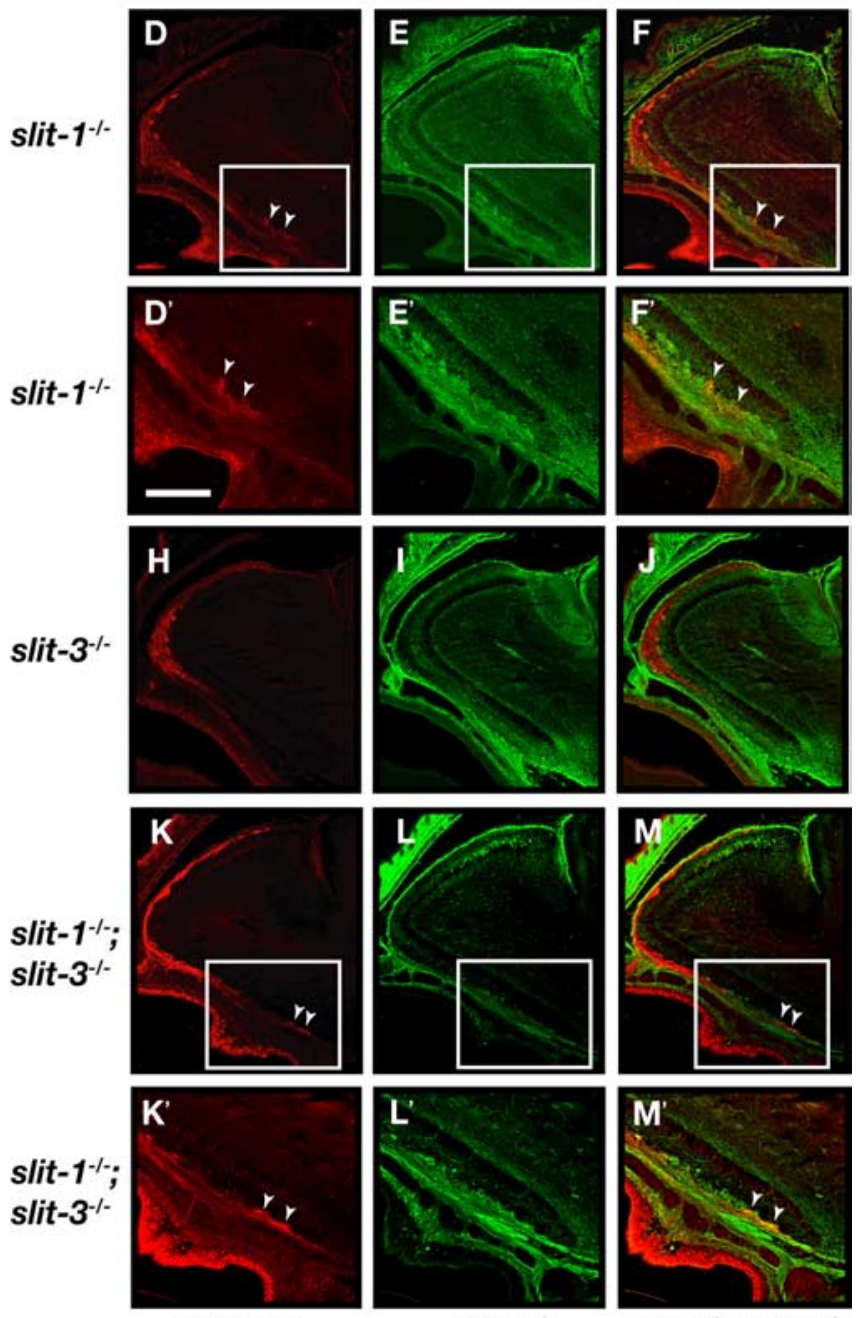

wild-type
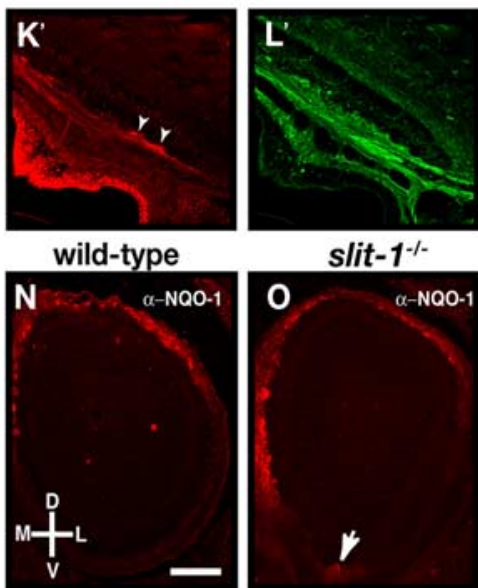

slit-1 1
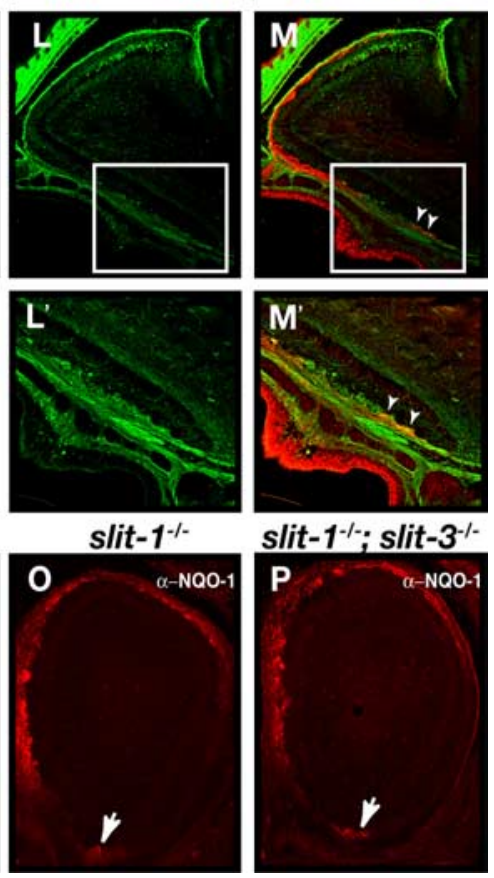

Figure 6. Loss of zonal targeting of NQ0-1-expressing olfactory sensory neuron axons within the olfactory bulb in slit- $1^{-1-}$ mice. $A-M$, Parasagittal sections of olfactory bulbs from P0

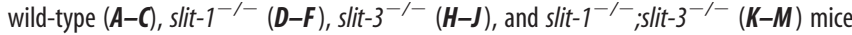
stained with anti-NQO-1 $(A, C, D, F, H, J, K, M)$ and anti-OCAM $(B, C, E, F, I, J, L, M)$. In wild-type animals, $\mathrm{NQO}-1$-expressing axons are restricted to the rostrodorsal region of the $\mathrm{OB}(A, C)$ and OCAM-expressing axons target to the ventral region of the olfactory bulb $(B, C$. Whereas NQO1-expressing axons are properly targeted to the dorsal region of the olfactory bulb in slit- $3^{-/-}$ mice $(\boldsymbol{H}, \boldsymbol{J})$, a subset of NQ0-1-expressing axons mistarget to the most ventral region of the olfactory bulb in slit- $1^{-/-}$mice $(\boldsymbol{D}, \boldsymbol{F})$ (arrowheads). In slit- $1^{-/-}$; slit- $3^{-/-}$mice, NQ0-1expressing axons are also observed in the ventral region of the olfactory bulb $(\boldsymbol{K}, \boldsymbol{M})$ (arrowheads). High-powered magnifications of ectopically projecting NQ0-1-expressing axons (insets in $\boldsymbol{D}, \boldsymbol{F}, \boldsymbol{K}, \boldsymbol{M}$ ) are shown in $\boldsymbol{D}^{\prime}, \boldsymbol{F}^{\prime}, \boldsymbol{K}^{\prime}$, and $\boldsymbol{M}^{\prime} . n=8$ wild type, $n=5$ slit- ${ }^{-/-}, n=8$
$\mathrm{OB}$ in wild-type mice, a subset of NQO-1-positive fibers are detected in the ventral region of the $\mathrm{OB}$ in slit-1 $1^{-/-}$and slit $-1^{-/-}$; slit- $3^{-/-}$mice (Fig. $6 N, O, P$ ). Mistargeted axons were observed in all mutant mice analyzed and at several levels along the rostrocaudal axis (supplemental Fig. 3, available at www.jneurosci.org as supplemental material). Interestingly, the defects observed in slit $-1^{-/-} ;$slit $-3^{-/-}$mice were similar in severity to those seen in slit- $1^{-/-}$mice, suggesting that Slit-3 is not required for targeting of NQO-1-expressing OSN axons. Furthermore, the defects observed are not attributable to deregulated expression of NQO-1, $O C A M$, and robo family members in the $\mathrm{OE}$ or of slits in the $\mathrm{OB}$ of these mice (Fig. $5 B, E, H, J, M, O, P$ ). In addition the zonal segregation of zone I OR expression was unaltered in slit-1 ${ }^{-/-}$mice (supplemental Fig. 2, available at www.jneurosci.org as supplemental material). Because Slit-1 is expressed at high levels in the ventral region of the $\mathrm{OB}$, these results suggest that Slit- 1 is required to prevent NQO-1-positive axons, which express high levels of Robo-2, from innervating the ventral region of the OB.

\section{Mistargeted NQO-1 axons form glomeruli in Slit and Robo-2} mutant mice

Our analyses of axonal projections in Robo-2 and Slit mutant mice at $\mathrm{P} 0$ shows that a subset of NQO-1-expressing axons ectopically enter the glomerular layer to form protoglomeruli in the ventral region of the $\mathrm{OB}$ in robo- $2^{-/-}$, slit- $1^{-/-}$, and slit- $1^{-/-}$; slit$3^{-/-}$mice (Figs. $4 D, J, M, 6 D, K, O, P$ ). However, it is unclear whether these axons are retained or pruned during maturation of the glomerular map. Because slit- $1^{-/-}$and a subset of slit- $1^{-/-}$; slit- $3^{-1-}$ mice survive to adulthood, we analyzed the targeting accuracy of NQO-1 axonal projections in adult mice. In contrast to wild-type mice, in which all NQO-1-positive glomeruli are located in the dorsomedial region of the OB, NQO-1-positive glomeruli are detected in the ventral region of the $\mathrm{OB}$ in both slit- $1^{-/-}$and slit- $1^{-/-} ;$slit- $3^{-/-}$mice (Fig. 7A-C,I-K,P,Q). Ectopic NQO-1-positive glomeruli are observed in the ventral region of $\mathrm{OB}$ sections representing a large proportion of the rostrocaudal axis of the $\mathrm{OB}$ in slit-1 $1^{-/-}$and slit- $1^{-/-} ;$slit- $3^{-/-}$mice (Fig. 7Q and data not shown). In addition, whereas a sharp border is observed between NQO-1- and OCAM-positive glomeruli in the medial side of the $\mathrm{OB}$ in wild-type mice, NQO-1- and OCAM-positive glomeruli are often intermingled in slit-1 $1^{-/-}$ and slit $-1^{-/-}$; slit- $3^{-/-}$mice (Fig. $7 \mathrm{~K}$ and data not shown). These defects were observed in adult mice up to 8 months of age, suggesting that they are unlikely to result from a delayed maturation of the glomerular map (supplemental Fig. 4, available at www. jneurosci.org as supplemental material) (Zou et al., 2004). Interestingly, although the majority of ectopically targeted NQO-1expressing axons form homogenous glomeruli containing strictly NQO-1-positive axons, heterogenous glomeruli containing both NQO-1- and OCAM-positive axons are also observed in all mutant mice analyzed (Fig. 7M,N). Furthermore, NQO-1expressing axons that ectopically target to the ventral region of the OB are SV2 positive, which is consistent with the possibility that they form synapses within glomeruli (Fig. 7O).

slit-3 $3^{-/-}$, and $n=7$ slit- $1^{-/-} ;$slit- $3^{-/-} . \mathbf{N}-\boldsymbol{P}$, Coronal sections at similar rostrocaudal levels of olfactory bulbs isolated from PO $(\boldsymbol{N}-\boldsymbol{P})$ wild-type $(\boldsymbol{N})$, slit- $1^{-/-}(\mathbf{0})$, and slit-1 ${ }^{-/-}$; slit$3^{-1-}(\boldsymbol{P})$ mice stained with anti-NQ0-1 (N-P). In wild-type mice, NQ0-1-expressing axons innervate the dorsomedial region of the olfactory bulb. In slit- $1^{-/-}$and $s$ lit- $1^{-/-} ;$slit- $3^{-1-}$ mice, a subset of NQ0-1-expressing axons are mistargeted to the ventral region of the olfactory bulb (arrows). $n=8$ wild type, $n=8$ slit- $1^{-1-}$, and $n=5$ slit- $1^{-1-} ;$ slit- $3^{-1-}$. D, Dorsal; $V$, ventral; L, lateral; M, medial; R, rostral; C, caudal. Scale bars, $250 \mu \mathrm{m}$. 


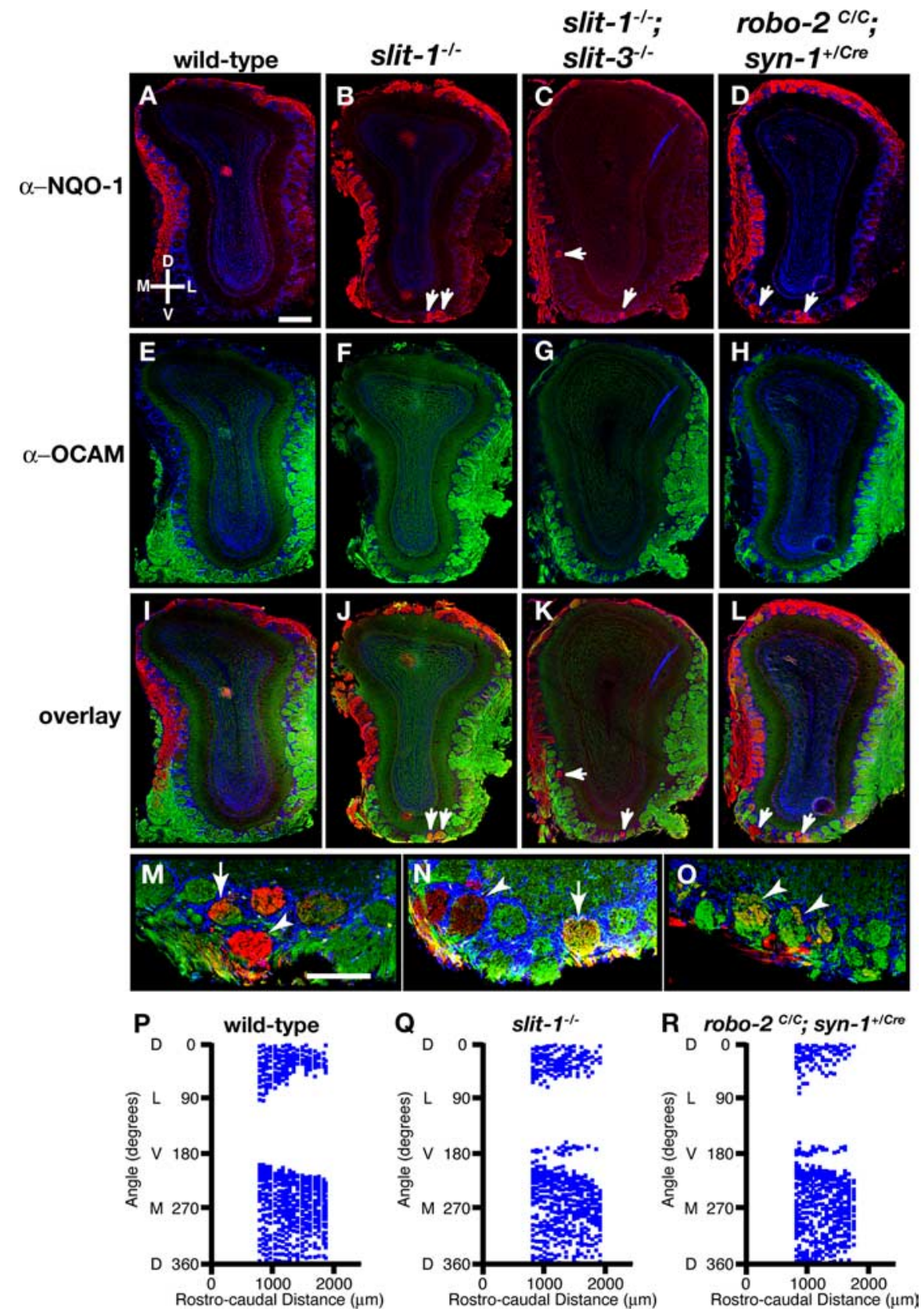

Figure 7. Mistargeted axons of NQ0-1-expressing olfactory sensory neurons innervate glomeruli in the ventral region of the olfactory bulb in slit and robo-2 mutant mice. Coronal sections at similar rostrocaudal levels of olfactory bulbs isolated from 8- to

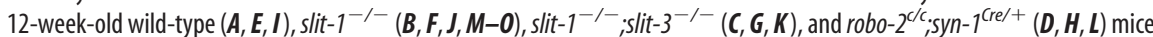
stained with anti-NQ0-1 $(\boldsymbol{A}-\boldsymbol{D}, \boldsymbol{I}-\boldsymbol{L}, \boldsymbol{M}-\mathbf{0})$, anti-OCAM $(\boldsymbol{E}-\boldsymbol{H}, \boldsymbol{I}-\boldsymbol{L}, \boldsymbol{M}, \boldsymbol{N})$, anti-SV2 $(\boldsymbol{0})$, and Hoechst $(\boldsymbol{A}-\mathbf{0})$. In wild-type mice, NQ0-1-expressing axons innervate glomeruli restricted to the dorsomedial region of the olfactory bulb $(\boldsymbol{A}, \boldsymbol{I})$, and 0 CAMexpressing axons innervate glomeruli in the ventrolateral region of the olfactory bulb $(\boldsymbol{E}, \boldsymbol{I})$. In slit-1 $1^{-/-}(\boldsymbol{B}, \boldsymbol{J})$, slit- $1^{-/-} ;$slit$3^{-/-}(\boldsymbol{C}, \boldsymbol{K})$, and robo-2 $2^{\mathrm{c} / \mathrm{c}} ;$ syn- $1^{\mathrm{Cre} /+}(\boldsymbol{D}, \boldsymbol{L})$ mice, a subset of NQ0-1-expressing axons are mistargeted to glomeruli in the ventral region of the olfactory bulb (arrows). NQ0-1-expressing axons that target ectopically in the ventral region of the $0 \mathrm{~B}$ in slit- $1^{-1-}$ mice form both homogenous (arrowheads) and heterogenous (arrows) glomeruli $(\boldsymbol{M}, \boldsymbol{N})$ and are positive for the presynaptic marker SV2, suggesting that they form synapses (arrowheads) (0). $n=10$ wild type, $n=14$ slit- $1^{-/-}, n=9$ slit- $1^{-/-}$; slit$3^{-1-}$, and $n=4$ robo- $2^{c / c} ;$ syn- $1^{\text {Cre/+ }}$. Scale bars: $\boldsymbol{A}-\boldsymbol{L}, 250 \mu \mathrm{m} ; \boldsymbol{M}-\mathbf{0}, 140 \mu \mathrm{m}$. $\boldsymbol{P}-\boldsymbol{R}$, Scatter plots showing the mapping of the positions of NQ0-1-positive glomeruli in the olfactory bulb of an adult wild-type $(\boldsymbol{P})$, slit- $1^{-/-}(\mathbf{Q})$, and robo- $2^{\mathrm{c} / \mathrm{c}} ;$ Syn- $1^{\mathrm{Cre} /+}(\boldsymbol{R})$ mouse. The relative positions of glomeruli containing NQ0-1-positive axons were assessed in olfactory bulb sections isolated over a rostrocaudal distance of $1000 \mu \mathrm{m}$ starting at $800 \mu \mathrm{m}$ from the tip of the olfactory bulb. Although NQ0-1-positive glomeruli are absent in the ventral region of the olfactory bulb ( $180^{\circ}$ angle) from a wild-type mouse, NQ0-1-positive glomeruli are consistently observed in the most ventral region of the OB in slit- $1^{-/-}$and robo- $2^{c / c} ;$ Syn- $1^{C r e /+}$ mice. Shown are representative plots from a single olfactory bulb for each genotype ( $n=4$ olfactory bulbs from 2 mice of each genotype). D, Dorsal; V, ventral; $L$, lateral; $M$, medial.
The perinatal lethality of robo- $2^{-/-}$ mice precluded us from evaluating the requirement for Robo-2 in the development of accurate NQO-1-expressing axonal projections in the adult olfactory glomerular map. We therefore selectively ablated expression of Robo-2 in neurons by generating robo- 2 conditional null mice that express the Cre (bacterio phage P1 cyclization recombinase) recombinase under the control of the pan-neuronal synapsin-1 $(s y n-1)$ promoter (Hoesche et al., 1993, 1995; Cloutier et al., 2004; Lu et al., 2007). robo- $2^{C / C} ;$ syn-1 $1^{\mathrm{Cre} /+}$ mice survive until adulthood, and their OBs are fully innervated by NQO-1- and OCAM-expressing axons. As observed in Slit mutant mice, a subset of NQO-1-positive axons mistarget to glomeruli in the ventral region of the $\mathrm{OB}$ in robo-2 $2^{\mathrm{C} / \mathrm{C}}$; syn-1 $\mathrm{Cre}^{\mathrm{Cl}}$ mice (Fig. $7 D, L, R)$. Together, these results show that Slit- 1 and Robo- 2 are required for the accurate formation of the mature olfactory glomerular map.

\section{Discussion}

The detection of sensory inputs requires the formation of stereotypic connections between sensory neurons in the periphery and second-order neurons of the CNS. A spatial relationship exists between the location of OSNs within the OE and their target glomeruli within the OB. OSNs of the dorsomedial aspect of the OE project dorsally within the OB, whereas OSNs located in the ventrolateral region of the $\mathrm{OE}$ send their axons to more ventral targets in the OB (Astic and Saucier, 1986; Saucier and Astic, 1986; Miyamichi et al., 2005). Although the molecular mechanism underlying the accurate sorting of these axons within the $\mathrm{OB}$ during development has not been identified, axon guidance cues represent good candidates to regulate this process. Our results show that the axon guidance receptor Robo-2 is expressed in a high dorsomedial to low ventrolateral gradient in the OE. Furthermore, the Robo- 2 ligands Slit-1 and Slit-3 are expressed at high levels in the ventral aspect of the OB, and both Slit-1 and Robo-2 expression are required for the segregation of NQO-1-expressing OSN axons to the dorsal region of the OB (Fig. 8). Together, our results demonstrate that Slit-1 and Robo-2 are required for accurate dorsal-to-ventral targeting of OSN axons within the $\mathrm{OB}$.

Expression patterns of Robo-2 and Slits in the olfactory system

OSNs expressing a specific OR are scattered within four spatially distinct zones of 

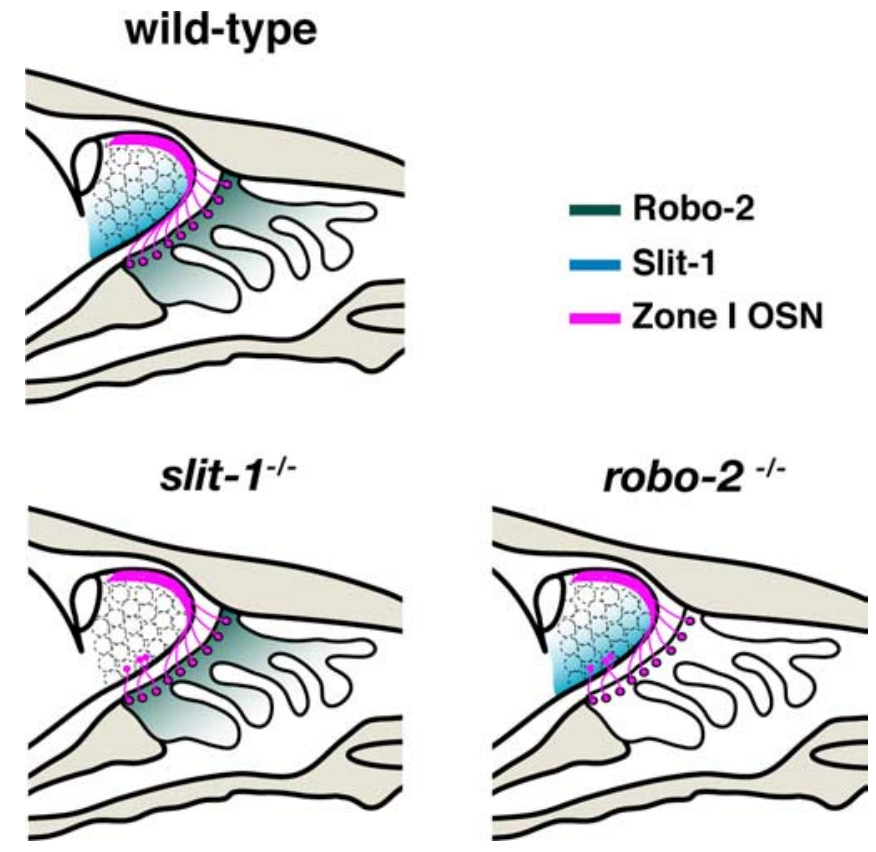

Figure 8. Slit-1 and Robo-2 are required for the segregation of zone IOSN axons to the dorsal region of the $O B$. Representation of zone I OSN projections in wild-type, slit- $1^{-1-}$, and robo$2^{-1-}$ mice. NQ0-1-expressing zone I OSNs (magenta) located in the dorsal region of the $\mathrm{OE}$ project their axons to the dorsal aspect of the $\mathrm{OB}$. The high dorsal to low ventral graded expression of Robo-2 (green) in OSN of the OE promotes the segregation of NQ0-1-expressing axons to the dorsal region of the OB. Zone I OSN axons may be repelled by the Robo-2 ligand Slit-1, which is expressed in the ventral region of the $0 \mathrm{~B}$. Loss of either Robo- 2 or Slit- 1 expression leads to mistargeting of a subset of zone I OSN axons to the ventral aspect of the $O B$.

the OE (Strotmann et al., 1992, 1994; Ressler et al., 1993; Vassar et al., 1993, 1994; Mombaerts et al., 1996; Sullivan et al., 1996; Tsuboi et al., 1999). Although initial studies suggested that these zones only partially overlap at their boundaries, recent results suggest that OR expression domains form a continuous gradient in the OE (Miyamichi et al., 2005). This observation raises the possibility that the dorsoventral segregation of OSN axons within the $\mathrm{OB}$ may be regulated through graded expression of axon guidance receptors in the $\mathrm{OE}$ and of their ligands in the $\mathrm{OB}$. Consistent with this notion, our results show that the Slit receptor Robo-2 is expressed in a gradient across the OE. The high dorsomedial to low ventrolateral expression of Robo-2 in the OE suggests that its expression may regulate dorsoventral targeting of OSNs within the bulb. Although the axon guidance receptor Npn-2 (neuropilin-2) is expressed in a gradient in specific regions of the OE (Norlin et al., 2001), our result represents the first example of an axon guidance receptor being expressed in a gradient across the defined zones of the OE. OSN axons expressing varying levels of Robo-2 may therefore respond differentially to the expression of Slits in the OB. Indeed, our results show that Slit- 1 and Slit- 3 are expressed in the ventral region of the developing $\mathrm{OB}$ at the stages of development when OSN axons reach and begin to enter the OB. Secretion of Slits by cells in the ventral region of the $\mathrm{OB}$, possibly by mitral cells, may promote the formation of a high ventral to low dorsal gradient of Slit proteins in the OB (Fig. 8). The levels of Robo-2 expressed on an OSN axon may therefore dictate its targeting location in the dorsoventral axis in response to a gradient of slit proteins within the OB.
Slit-1 and Robo-2 control dorsoventral segregation of olfactory sensory neuron axons in the olfactory bulbs The graded pattern of expression of Robo- 2 in the OE and the expression of its ligands Slit- 1 and Slit- 3 in the OB suggest that Slit-Robo signaling may direct targeting of OSN axons within the OB. Because Robo-2 is highly expressed in OSNs located in the dorsomedial region of the OE that expresses NQO-1, we evaluated the accuracy of targeting of NQO-1-expressing axons in robo- $2^{-1-}$, slit- $1^{-1-}$, and slit- $3^{-1-}$ mice. Our analyses revealed that a subset of NQO-1-expressing axons mistarget to the ventral region of the $\mathrm{OB}$ in the absence of Robo-2. Furthermore, Slit-1, but not Slit-3, is required to segregate axons of NQO-1expressing OSNs to the dorsal region of the OB. Indeed, ablation of both Slit-1 and Slit-3 does not lead to more severe defects in targeting of NQO-1-expressing axons when compared with the single ablation of Slit-1, indicating that Slit-1 is the major contributor to Robo-2-mediated segregation of OSN axons within the OB. This observation suggests that different members of the Slit family may bind to Robos with various efficiencies in vivo despite having similar binding affinities for these receptors in vitro. Alternatively, Slit-1 and Slit-3 may be secreted at different levels in the ventral region of the OB. Nonetheless, we cannot exclude the possibility that Slit-3 is required for sorting of OCAM-expressing axons within the more ventral regions of the $\mathrm{OB}$.

In contrast to NQO-1-expressing OSN axons, the ventral segregation of OCAM-expressing OSN axons does not appear to be grossly affected in slit-1 $1^{-/-}$and robo- $2^{-/-}$mice. Indeed, we did not observe mistargeting of OCAM-expressing axons to the more dorsal region of the $\mathrm{OB}$ in these mice. This observation raises the interesting possibility that another set of guidance cues may promote the segregation of OCAM-expressing axons to the ventral region of the OB. Although OCAM-expressing axons appear to be properly segregated to the ventral region of the $\mathrm{OB}$, it is possible that these axons mistarget within this region in slit- $1^{-/-}$and robo- $2^{-/-}$mice. In fact, if Slit-1-Robo-2 signaling is required for the zonal segregation of all OSN axons within the OB, we would expect that targeting accuracy within OCAM-positive regions of the OB (zones II-IV) should also be affected. Moreover, our analyses of NQO-1-positive axonal projections in mutant mice do not exclude the possibility that Slit-1-Robo-2 signaling can also control targeting of OSN axons in other axes of the OB. To address these questions, it will be necessary to evaluate the accuracy of targeting of specific populations of OSN axons in slit-1 ${ }^{-/-}$ mice using $\mathrm{OR}$-taulacZ reporter mice.

Although the mistargeting of NQO-1-expressing axons to the ventral region of the $\mathrm{OB}$ observed in robo- $2^{-/-}$mice is likely to result from the inability of OSN axons to respond to Slits in the $\mathrm{OB}$, we cannot exclude the possibility that the stunted development of the OB observed in robo- $2^{-1-}$ mice may also affect axonal targeting. Nonetheless, the observation that ablation of Slit-1 expression also leads to mistargeting of NQO-1-expressing axons, despite the normal size of the $\mathrm{OB}$ in slit- $1^{-/-}$mice, strongly suggests that Slit-1-Robo-2 interactions are required for accurate targeting of these axons within the bulb. Future experiments involving the genetic ablation of Robo-2 expression exclusively in OSNs should shed more light on the cell-autonomous requirement of Robo-2 for segregation of OSN axons in the OB.

We also cannot exclude the possibility that expression of a specific subset of zone I ORs may be lost in slit-1 $1^{-1-}$ and robo$2^{-/-}$mice, leading to the mistargeting of this subset of axons. However, OSN axons lacking OR expression have been shown previously to remain in the olfactory nerve layer and do not enter 
glomeruli in the OB (Wang et al., 1998). Because the NQO-1expressing axons that erroneously target to the ventral region of the $\mathrm{OB}$ in $\mathrm{slit}-1^{-/-}$and robo- $2^{\mathrm{C} / \mathrm{C}} ; \mathrm{syn}-1^{\mathrm{Cre} /+}$ mice coalesce into glomeruli and appear to form synapses, they are likely to still express an OR.

It is interesting to note that, in addition to the mistargeting of a subset of NQO-1-expressing axons within the OB, robo-2 $2^{-/-}$ mice show additional defects that are not observed in $s$ lit $-1^{-1-}$ mice. These include smaller olfactory bulbs and a lack of innervation of some regions that are innervated by OCAM-expressing axons in wild-type mice. This observation would suggest that Robo-2 may have both Slit-1-dependent and -independent functions during development of OSN projections. Indeed, Robo-2 has been shown to have the capacity to function as an adhesion molecule and could therefore be involved in promoting the sorting of axons in the nerve layer as well as their entry into the glomerular layer of the OB (Hivert et al., 2002). Alternatively, these differences in phenotypes may result from the differential expression of Robo-2 in several types of cells such as neurons or glia. Our observation that selective ablation of Robo-2 expression in neurons does not affect innervation of the OB by OCAMexpressing axons seems to support this possibility.

\section{Axon guidance cues in the generation of the glomerular map}

The formation of stereotypic connections between olfactory sensory neurons and mitral/tufted cells within the OB is tightly regulated. The glomerular map that is formed requires axons to find their precise target within a complex three-dimensional field. This accurate targeting relies on the expression of ORs in OSNs and on their ability to respond to axonal guidance cues. Several axon guidance molecules such as Sema3A (Schwarting et al., 2000, 2004), Ephrin As (Cutforth et al., 2003), and now Slits, appear to be required for proper development of the glomerular map. Whereas Ephrin As have been implicated in the regulation of anteroposterior targeting of OSN axons (Cutforth et al., 2003), Sema3A is required for accurate mediolateral compartmentalization of OSN axons within the OB (Schwarting et al., 2000, 2004). Here, we provide evidence that Slit-1-Robo-2 signaling promotes the zonal segregation of OSNs in the dorsoventral axis of the OB. It is likely that Slit-1 and Robo- 2 collaborate with other families of axon guidance cues to direct accurate dorsoventral targeting of OSN axons within the bulb. Indeed, our observation that a large proportion of NQO-1-expressing axons target appropriately to the dorsal region of the OB in the absence of Slit- 1 or Robo-2 suggests that long-range attractant cues may also promote their segregation to the dorsal region of the OB.

In addition to axon guidance cues, expression of OR plays a critical role for the accurate coalescence of axons into specific glomeruli (Mombaerts et al., 1996). It has been proposed that ORs may regulate targeting of OSN axons through OR-mediated interactions between OSN axons (Feinstein and Mombaerts, 2004; Feinstein et al., 2004). Our observation that the mistargeted NQO-1-positive axons observed in adult slit- $1^{-1-}$ and robo-2 $2^{C / C}$; $s y n-1^{\mathrm{Cre} /+}$ mice form heterogenous glomeruli with OCAMpositive axons suggests that expression of an OR is not sufficient to ensure homogenous coalescence of axons into glomeruli. It is possible that Slit-1-Robo-2 signaling serves to promote the initial segregation of OSN axons in the dorsoventral axis of the OB, which is followed by coalescence of axons into glomeruli through OR-mediated interactions. However, recent results suggest that OR-dependent G-protein signaling leading to changes in intracellular cAMP levels can also regulate the anteroposterior targeting of OSN axons within the OB (Imai et al., 2006; Chesler et al.,
2007; Dal Col et al., 2007; Zou et al., 2007). Although it is unclear how OR-induced G-protein signaling mediates this effect, it may do so by modulating signals generated by axon guidance receptors. For example, in Drosophila, expression of an activated form of the G-protein dgq $\alpha 3$ antagonizes Robo signaling, thereby leading to axonal pathfinding defects at the midline (Ratnaparkhi et al., 2002). Alternatively, the regulation of intracellular cAMP levels may be important for expression of specific axon guidance molecules and their receptors, such as Neuropilin-1 (Imai et al., 2006; Dal Col et al., 2007). Interestingly, modulating cAMP levels does not affect the dorsoventral targeting of OSN axons, suggesting that Robo-2 expression in OSNs is unlikely to be regulated by intracellular levels of cAMP (Imai et al., 2006; Chesler et al., 2007; Dal Col et al., 2007; Zou et al., 2007). OR molecules may also promote the accurate coalescence of axons by regulating the expression of homophilic adhesion molecules and repulsive guidance cues, such as Ephrin As, in OSNs (Serizawa et al., 2006).

Together, our results demonstrate that the dorsoventral segregation of OSN axons within the $\mathrm{OB}$ is not only dependent on the anatomical locations of OSNs within the OE but also on their ability to process guidance information provided by their surroundings. Additional studies will address potential interactions between the different families of axon guidance molecules involved in the development of connectivity in the olfactory system.

\section{References}

Alenius M, Bohm S (1997) Identification of a novel neural cell adhesion molecule-related gene with a potential role in selective axonal projection. J Biol Chem 272:26083-26086.

Astic L, Saucier D (1986) Anatomical mapping of the neuroepithelial projection to the olfactory bulb in the rat. Brain Res Bull 16:445-454.

Brose K, Bland KS, Wang KH, Arnott D, Henzel W, Goodman CS, TessierLavigne M, Kidd T (1999) Slit proteins bind Robo receptors and have an evolutionarily conserved role in repulsive axon guidance. Cell 96:795-806.

Chesler AT, Zou D-J, Le Pichon CE, Peterlin ZA, Matthews GA, Pei X, Miller MC, Firestein S (2007) A G protein/camp signal cascade is required for axonal convergence into olfactory glomeruli. Proc Natl Acad Sci USA 104:1039-1044.

Cloutier J-F, Giger RJ, Koentges G, Dulac C, Kolodkin AL, Ginty DD (2002) Neuropilin-2 mediates axonal fasciculation, zonal segregation, but not axonal convergence, of primary accessory olfactory neurons. Neuron 33:877-892.

Cloutier J-F, Sahay A, Chang EC, Tessier-Lavigne M, Dulac C, Kolodkin AL, Ginty DD (2004) Differential requirements for semaphorin $3 \mathrm{~F}$ and Slit-1 in axonal targeting, fasciculation, and segregation of olfactory sensory neuron projections. J Neurosci 24:9087-9096.

Cutforth T, Moring L, Mendelsohn M, Nemes A, Shah NM, Kim MM, Frisen J, Axel R (2003) Axonal ephrin-As and odorant receptors: coordinate determination of the olfactory sensory map. Cell 114:311-322.

Dal Col JA, Matsuo T, Storm DR, Rodriguez I (2007) Adenylyl cyclasedependent axonal targeting in the olfactory system. Development 134:2481-2489.

de Castro F, Hu L, Drabkin H, Sotelo C, Chedotal A (1999) Chemoattraction and chemorepulsion of olfactory bulb axons by different secreted semaphorins. J Neurosci 19:4428-4436.

Feinstein P, Mombaerts P (2004) A contextual model for axonal sorting into glomeruli in the mouse olfactory system. Cell 117:817-831.

Feinstein P, Bozza T, Rodriguez I, Vassalli A, Mombaerts P (2004) Axon guidance of mouse olfactory sensory neurons by odorant receptors and the beta2 adrenergic receptor. Cell 117:833-846.

Grieshammer U, Le M, Plump AS, Wang F, Tessier-Lavigne M, Martin GR (2004) SLIT2-mediated ROBO2 signaling restricts kidney induction to a single site. Dev Cell 6:709-717

Gussing F, Bohm S (2004) NQO1 activity in the main and the accessory olfactory systems correlates with the zonal topography of projection maps. Eur J Neurosci 19:2511-2518.

Hivert B, Liu Z, Chuang CY, Doherty P, Sundaresan V (2002) Robol and 
Robo2 are homophilic binding molecules that promote axonal growth. Mol Cell Neurosci 21:534-545.

Hoesche C, Sauerwald A, Veh RW, Krippl B, Kilimann MW (1993) The 5 '-flanking region of the rat synapsin I gene directs neuron-specific and developmentally regulated reporter gene expression in transgenic mice. J Biol Chem 268:26494-26502.

Hoesche C, Bartsch P, Kilimann MW (1995) The CRE consensus sequence in the synapsin I gene promoter region confers constitutive activation but no regulation by cAMP in neuroblastoma cells. Biochim Biophys Acta 1261:249-256.

Imai T, Suzuki M, Sakano H (2006) Odorant receptor-derived cAMP signals direct axonal targeting. Science 314:657-661.

Iwema CL, Fang H, Kurtz DB, Youngentob SL, Schwob JE (2004) Odorant receptor expression patterns are restored in lesion-recovered rat olfactory epithelium. J Neurosci 24:356-369.

Jhaveri D, Saharan S, Sen A, Rodrigues V (2004) Positioning sensory terminals in the olfactory lobe of Drosophila by Robo signaling. Development 131:1903-1912.

Lu W, van Eerde AM, Fan X, Quintero-Rivera F, Kulkarni S, Ferguson H, Kim H-G, Fan Y, Xi Q, Li QG, Sanlaville D, Andrews W, Sundaresan V, Bi W, Yan J, Giltay JC, Wijmenga C, de Jong TP, Feather SA, Woolf AS, Rao Y, Lupski JR, Eccles MR, Quade BJ, Gusella JF, Morton CC, Maas RL (2007) Disruption of $\mathrm{ROBO} 2$ is associated with urinary tract anomalies and confers risk of vesicoureteral reflux. Am J Hum Genet 80:616-632.

Marillat V, Cases O, Nguyen-Ba-Charvet KT, Tessier-Lavigne M, Sotelo C, Chedotal A (2002) Spatiotemporal expression patterns of slit and robo genes in the rat brain. J Comp Neurol 442:130-155.

Miyamichi K, Serizawa S, Kimura HM, Sakano H (2005) Continuous and overlapping expression domains of odorant receptor genes in the olfactory epithelium determine the dorsal/ventral positioning of glomeruli in the olfactory bulb. J Neurosci 25:3586-3592.

Miyasaka N, Sato Y, Yeo SY, Hutson LD, Chien CB, Okamoto H, Yoshihara Y (2005) Robo2 is required for establishment of a precise glomerular map in the zebrafish olfactory system. Development 132:1283-1293.

Mombaerts P, Wang F, Dulac C, Chao SK, Nemes A, Mendelsohn M, Edmondson J, Axel R (1996) Visualizing an olfactory sensory map. Cell 87:675-686.

Norlin EM, Berghard A (2001) Spatially restricted expression of regulators of G-protein signaling in primary olfactory neurons. Mol Cell Neurosci 17:872-882.

Norlin EM, Alenius M, Gussing F, Hagglund M, Vedin V, Bohm S (2001) Evidence for gradients of gene expression correlating with zonal topography of the olfactory sensory map. Mol Cell Neurosci 18:283-295.

Pasterkamp RJ, Ruitenberg MJ, Verhaagen J (1999) Semaphorins and their receptors in olfactory axon guidance. Cell Mol Biol (Noisy-le-grand) 45:763-779.

Plump AS, Erskine L, Sabatier C, Brose K, Epstein CJ, Goodman CS, Mason CA, Tessier-Lavigne M (2002) Slit1 and Slit2 cooperate to prevent premature midline crossing of retinal axons in the mouse visual system. Neuron 33:219-232.

Ratnaparkhi A, Banerjee S, Hasan G (2002) Altered levels of $\mathrm{G}_{\mathrm{q}}$ activity modulate axonal pathfinding in Drosophila. J Neurosci 22:4499-4508.

Renzi MJ, Wexler TL, Raper JA (2000) Olfactory sensory axons expressing a dominant-negative semaphorin receptor enter the CNS early and overshoot their target. Neuron 28:437-447.

Ressler KJ, Sullivan SL, Buck LB (1993) A zonal organization of odorant receptor gene expression in the olfactory epithelium. Cell 73:597-609.

Ressler KJ, Sullivan SL, Buck LB (1994) Information coding in the olfactory system: evidence for a stereotyped and highly organized epitope map in the olfactory bulb. Cell 79:1245-1255.
Saucier D, Astic L (1986) Analysis of the topographical organization of olfactory epithelium projections in the rat. Brain Res Bull 16:455-462.

Schaefer ML, Finger TE, Restropo D (2001) Variability of position of the P2 glomerulus within a map of the mouse olfactory bulb. J Comp Neurol 436:351-362.

Schwarting GA, Kostek C, Ahmad N, Dibble C, Pays L, Puschel AW (2000) Semaphorin $3 \mathrm{~A}$ is required for guidance of olfactory axons in mice. J Neurosci 20:7691-7697.

Schwarting GA, Raitcheva D, Crandall JE, Burkhardt C, Puschel AW (2004) Semaphorin 3A-mediated axon guidance regulates convergence and targeting of P2 odorant receptor axons. Eur J Neurosci 19:1800-1810.

Serizawa S, Miyamichi K, Takeuchi H, Yamagishi Y, Suzuki M, Sakano H (2006) A neuronal identity code for the odorant receptor-specific and activity-dependent axon sorting. Cell 127:1057-1069.

Strotmann J, Wanner I, Krieger J, Raming K, Breer H (1992) Expression of odorant receptors in spatially restricted subsets of chemosensory neurons. NeuroReport 3:1053-1056.

Strotmann J, Wanner I, Helfrich T, Beck A, Breer H (1994) Rostro-caudal patterning of receptor-expressing olfactory neurones in the rat nasal cavity. Cell Tissue Res 278:11-20.

Sullivan SL, Adamson MC, Ressler KJ, Kozak CA, Buck LB (1996) The chromosomal distribution of mouse odorant receptor genes. Proc Natl Acad Sci USA 93:884-888.

Tsuboi A, Yoshihara S, Yamazaki N, Kasai H, Asai-Tsuboi H, Komatsu M, Serizawa S, Ishii T, Matsuda Y, Nagawa F, Sakano H (1999) Olfactory neurons expressing closely linked and homologous odorant receptor genes tend to project their axons to neighboring glomeruli on the olfactory bulb. J Neurosci 19:8409-8418.

Vassar R, Ngai J, Axel R (1993) Spatial segregation of odorant receptor expression in the mammalian olfactory epithelium. Cell 74:309-318.

Vassar R, Chao SK, Sitcheran R, Nunez JM, Vosshall LB, Axel R (1994) Topographic organization of sensory projections to the olfactory bulb. Cell 79:981-991.

Walz A, Rodriguez I, Mombaerts P (2002) Aberrant sensory innervation of the olfactory bulb in neuropilin-2 mutant mice. J Neurosci 22:4025-4035.

Wang F, Nemes A, Mendelsohn M, Axel R (1998) Odorant receptors govern the formation of a precise topographic map. Cell 93:47-60.

Yoshihara Y, Kawasaki M, Tamada A, Fujita H, Hayashi H, Kagamiyama H, Mori K (1997) OCAM: a new member of the neural cell adhesion molecule family related to zone-to-zone projection of olfactory and vomeronasal axons. J Neurosci 17:5830-5842.

Yuan W, Zhou L, Chen JH, Wu JY, Rao Y, Ornitz DM (1999) The mouse SLIT family: secreted ligands for ROBO expressed in patterns that suggest a role in morphogenesis and axon guidance. Dev Biol 212:290-306.

Yuan W, Rao Y, Babiuk RP, Greer JJ, Wu JY, Ornitz DM (2003) A genetic model for a central (septum transversum) congenital diaphragmatic hernia in mice lacking Slit3. Proc Natl Acad Sci USA 100:5217-5222.

Zheng C, Feinstein P, Bozza T, Rodriguez I, Mombaerts P (2000) Peripheral olfactory projections are differentially affected in mice deficient in a cyclic nucleotide-gated channel subunit. Neuron 26:81-91.

Zou D-J, Feinstein P, Rivers AL, Mathews GA, Kim A, Greer CA, Mombaerts P, Firestein S (2004) Postnatal refinement of peripheral olfactory projections. Science 304:1976-1979.

Zou D-J, Chesler AT, Le Pichon CE, Kuznetsov A, Pei X, Hwang EL, Firestein S (2007) Absence of adenylyl cyclase 3 perturbs peripheral olfactory projections in mice. J Neurosci 27:6675-6683.

Zou Z, Horowitz LF, Montmayeur JP, Snapper S, Buck LB (2001) Genetic tracing reveals a stereotyped sensory map in the olfactory cortex. Nature 414:173-179. 